\title{
The Hyaluronan-Related Genes HAS2, HYAL1-5, HYALP1 are Associated with Prognosis, Cell Viability and Spheroid Formation Capacity in Ovarian Cancer
}

\section{Jette Riecks}

Universitatsklinikum Munster

\section{Balázs Győrffy}

Semmelweis University: Semmelweis Egyetem

\section{Ludwig Kiesel}

Universitätsklinikum Münster: Universitatsklinikum Munster

\section{Alberto Passi}

University of Insubria: Universita degli Studi dell'Insubria

\section{Davide Vigetti}

University of Insubria: Universita degli Studi dell'Insubria

Martin Götte ( $\nabla$ mgotte@uni-muenster.de)

Universitätsklinikum Münster https://orcid.org/0000-0003-2360-2496

\section{Research Article}

Keywords: ovarian cancer, hyaluronidases, hyaluronan synthases, HAS2, gene expression, survival analysis

Posted Date: December 21st, 2021

DOI: https://doi.org/10.21203/rs.3.rs-1180717/v1

License: (c) (1) This work is licensed under a Creative Commons Attribution 4.0 International License. Read Full License 


\title{
The hyaluronan-related genes HAS2, HYAL1-5, HYALP1 are associated with prognosis, cell viability and spheroid formation capacity in ovarian cancer
}

\author{
Jette Riecks ${ }^{1}$, Balázs Győrffy (ORCID: 0000-0002-5772-3766) ${ }^{2,3,4}$, Ludwig Kiesel (ORCID: 0000-0002- \\ 7247-9247) ${ }^{1}$, Alberto Passi (ORCID: 0000-0003-3328-3089) ${ }^{5}$, Davide Vigetti (ORCID: 0000-0002-6339- \\ 8453) ${ }^{5}$, Martin Götte (ORCID: 0000-0003-2360-2496) ${ }^{1 *}$
}

1 Department of Gynecology and Obstetrics, Münster University Hospital, Albert-Schweitzer-Campus 1, 11, 48149, Münster, Germany.

2 Department of Bioinformatics, Semmelweis University, Budapest, Hungary.

3 2nd Department of Pediatrics, Semmelweis University, Budapest, Hungary.

4 TTK Momentum Cancer Biomarker Research Group, Budapest, Hungary.

5 Department of Medicine and Surgery, University of Insubria, Varese, Italy.

* corresponding author: Prof. Dr. M. Götte, Department of Gynecology and Obstetrics, Münster University Hospital, Albert-Schweitzer-Campus 1, 11, 48149, Münster, Germany. mgotte@ uni-muenster.de.

Acknowledgements We would like to acknowledge Birgit Pers for expert technical assistance and Nancy Espinoza-Sanchez for help with data analysis. We would like to state that the results published in this work are the subject of the inaugural dissertation to be handed in to Westphalian Wilhelms-University of Muenster by Jette Riecks. Open Access funding was enabled and organized by Projekt DEAL. The research was financed by the 2018-2.1.17-TET-KR-00001 grant and by the Higher Education Institutional Excellence Programme (20204.1.1.-TKP2020) of the Ministry for Innovation and Technology in Hungary (to BG), by the Open Access Publishing Fonds of the WWU Münster, and by EU H2020 MSCA RISE project \#645756 GLYCANC (to MG, AP).

\begin{abstract}
Purpose: Hyaluronan modulates tumor progression, including cell adhesion, cohesion, proliferation and invasion, and the cancer stem cell phenotype. In ovarian cancer, high levels of stromal hyaluronan are associated with poor prognosis. In this work hyaluronan synthases (HAS1-3) and hyaluronidases (HYAL1-5, HYALP1) were examined with regard to different levels of gene expression and its influence on ovarian cancer patients survival. The impact of a siRNA depletion of hyaluronic acid synthase HAS2 was investigated in vitro.

Methods: Using the Kaplan Meier Plotter tool, we investigated the influence of hyaluronic synthesis enzymes on the survival of a collective of 1435 ovarian cancer patients. We studied SKOV3 ovarian cancer cells subjected to HAS2 siRNA or control siRNA treatment in terms of HAS1-3, HYAL2 and HYAL3 mRNA expression. We investigated the ability to form spheroids using the Hanging Drop method and the response to chemotherapy at different concentrations using the MTT Assay. By String analysis, interactions within the enzymes of the hyaluronic acid system and with binding partners were visualized.

Results: HAS2 improves cell viability, the capability to form tumor spheroids and has a negative prognostic value regarding overall survival. Lower HAS2 expression and high expression of HYAL2 and HYAL3 favours the survival of ovarian cancer patients. HAS2 knockdown cells and control cells showed a moderate response to in vitro chemotherapy with Taxol, Cisplatin and combinatorial treatment.

Conclusion: In conclusion our study shows that the hyaluronic acid system has a relevant influence on the survival of ovarian cancer patients and could therefore be considered as a possible prognostic factor.
\end{abstract}

Keywords: ovarian cancer, hyaluronidases, hyaluronan synthases, HAS2, gene expression, survival analysis

\section{ABBREVIATIONS}

$\begin{array}{ll}\text { HAS } & \text { hyaluronan synthase } \\ \text { HR } & \text { Hazard Ratio } \\ \text { HYAL } & \text { hyaluronidase } \\ \text { OS } & \text { overall survival } \\ \text { PFS } & \text { progression free survival } \\ \text { qPCR } & \text { quantitative real time PCR }\end{array}$




\section{INTRODUCTION}

Ovarian cancer is the second deadliest gynecological tumor after breast cancer. (1) 75\% of carcinomas are detected at an advanced stage since the symptoms are very unspecific. In total, one of 72 women comes down with ovarian cancer. The relative 5-year survival rate is $43 \%$. (Wagner and Reuß, 2019), (S. G. Vitale et al., 2019)

In 2020, the global incidence was 6.6 and the mortality was 4.2 referred to 100000 people of all age groups. (WHO, international Agency for Research on Cancer, CANCER TODAY, no date, https://gco.iarc.fr/today/home, retrieved on 16.12.2021)

The common therapy is an operative resection or a systemic therapy that consists of a platinum-containing combination therapy (Carboplatin/Paclitaxel) or monotherapy. Patients, who show recurrence in the first half year, are probably platinum resistant. For these, a non platinum-containing monotherapy (e.g. Paclitaxel) is recommended. Patients without this resistance get platinum-containing combination therapy case of recurrence. (Wagner and Reuß, 2019), (S. G. Vitale et al., 2019)

With regard to the recurrence and aggressiveness of ovarian cancer it is important to understand the metastatic and proliferative pathways of ovarian cancer. An important factor for cell stability, self-renewal and cohesion of cells is the extracellular matrix. One central component of the extracellular matrix is hyaluronan. Hyaluronan acid is a glycosaminoglycan, consisting of repeating disaccharide chains of $\mathrm{N}$-acetyl-glucosamine and glucuronic acid. Hyaluronan has various molecular weight and size, and its function depends on available binding proteins and cell surface receptors. It is important for cell adhesion, motility, differentiation and the modulation of inflammation. (Garantziotis and Savani, 2019), (Ween, Oehler and Ricciardelli, 2011), (Tavianatou et al., 2019)

Hyaluronan is synthesized at the plasma membrane by three isoenzymes named hyaluronan synthases HAS1, HAS2, and HAS3, and is degraded by the hyaluronidases HYAL1-5, HYALP1 and TMEM1. (Garantziotis and Savani, 2019), (Yamaguchi et al., 2019)

The HASes show differences with respect to average sizes of hyaluronan and synthesis rate. HAS1 is the least active one. HAS2 is especially important during development. In mouse experiments, it was shown that there is a correlation between HAS2 expression and heart and limb development (Matsumoto et al., 2009). HAS2 appears to be the most important and catalytically active synthase isoenzyme in adult tissue. It produces high molecular mass hyaluronic acid and is a finely regulated enzyme. (Caon et al., 2021) HAS3 synthesizes hyaluronan that has a low molecular mass. (Triggs-Raine, 2015)

There are many different hyaluronidases. HYAL1 is an endoglycosidase that is active at an acidid pH. It was found in lysosomes, serum and in the extravascular space. In case of HYAL1 deficiency lysosomal storage disorder mucopolysaccharidosis IX and arthritis in children may occur. HYAL1 leads to an increased allergic inflammation in skin. Additionally its degradation of hyaluronan supports the elimination of bacterial skin infections.(Garantziotis and Savani, 2019) HYAL2 has an acidid pH and is a GPI anchored protein. It is necessary for thrombopoesis and degrades high molecular weight hyaluronan into intermediate size hyaluronan. This is then further degraded by HYAL1. (Garantziotis and Savani, 2019) HYAL3 is weakly expressed by somatic cells, and no activity has been detected so far. Nevertheless, experiments with hamster kidney cells showed that high expression of HYAL3 correlates with high expression of HYAL1. This could be an indication of a role in the hyaluronic acid system for HYAL3. (Triggs-Raine, 2015)(Hemming et al., 2008) HYAL4 is specific for chondroitin sulfate $\mathrm{C}$ and $\mathrm{D}$, but not for hyaluronan. It is synthesized in placental, skeletal muscle and testis. (Kaneiwa et al., 2010) HYAL 5 is a GPI anchored protein and is also known as SPAM1. It is active at neutral and acidid $\mathrm{pH}$ and is important for fertilization of the oocyte by sperm.(Garantziotis and Savani, 2019) HYALP1 is expressed in the testis and is localized on the plasma membrane of the anterior head of sperms. It is involved in the progesterone-induced hyaluronan enhanced acrosome reaction. (Miller, Shao and Martin-Deleon, 2006, p. 1) TMEM2 is a newly discovered surface protein that also shows high hyaluronidase activity. (Yamaguchi et al., 2019)

Some previous studies have pointed at the relevance of the enzymes of the hyaluronic acid system for ovarian cancer, which are presented below.

Ilana Weiss and others found that in serous ovarian cancer cells HAS1 is overexpressed in effusions, HAS2 in solid metastases and HAS3 in primary carcinomas and effusions. HYAL1 could not be detected at all. HYAL2 was present in two variants, with HYAL2-var2 being overexpressed in solid metastases. HYAL3 expression could also be detected. In addition, a change in expression due to chemotherapy treatment could be detected in this project: HAS1 was overexpressed in effusions before treatment compared to after, and the reverse was true for HYAL2-var1 and HYAL3. A high HYAL2-var1 correlated with longer overall survival and a high HAS1 expression with lower overall survival. (Weiss et al., 2012)

Another research group was able to show, on the basis of immunostaining, that HAS1 appears to have an influence on angiogenesis in ovarian carcinomas and correlates negatively with overall survival. In addition, they found that HAS1-3 expression has no effect on chemotherapy response. (Yabushita et al., 2004) 
Furthermore, it was conceived that in tissue that normally does not contain hyaluronic acid, the hyaluronic acid level also increases with increasing malignancy of the tumor. This also applies to tumor stroma, as in ovarian carcinoma. Overall, this hyaluronic acid accumulation correlates with a poor prognosis for the patient. (Tammi $e t$ al., 2008)

While these studies indicate a potentially important role for hyaluronan synthesis and degradation in ovarian cancer, no comprehensive analysis of the prognostic impact of hyaluronan synthases and hyaluronidases in a large collective of ovarian cancer patients has been performed. Moreover, the functional impact of the major hyaluronan synthase HAS2 in ovarian cancer cells is so far unclear.

In this project the influence of gene expression of hyaluronan enzymes on overall survival and progression free survival of ovarian cancer patients was analyzed by using the Kaplan-Meier-Plotter online database comprising gene expression and survival data of 1435 ovarian cancer patients. (Győrffy, Lánczky and Szállási, 2012). At the molecular level, we compared control SKOV3 cells and HAS2 knockdown cells regarding gene expression of HAS1-3 and HYAL2-3 by qPCR (quantitative real time PCR). Moreover, we analyzed the ability to form spheroids by using the Hanging Drop method. We furthermore investigated the cell viability of HAS2 knockdown cells compared to control cells under treatment with different chemotherapy regimens by MTT assay.

\section{MATERIAL \& METHODS}

\section{Kaplan-Meier-Plotter analysis}

Kaplan Meier Plotter (https://kmplot.com/analysis/, accessed on 11.04.2021) is a publicly accessible database that integrates gene expression data and survival information of 1435 ovarian cancer patients downloaded from the public repository Gene Expression Omnibus (GEO). (Győrffy, Lánczky and Szállási, 2012)

The tool allows to analyse overall survival (=OS) and progression free survival (=PFS) of ovarian cancer patients using different stratifications. Related to the enzymes of the hyaluronic acid system of ovarian cancer patients, there is data of 1435 patients for overall survival and 655 for progression free survival.

The patient data is divided into two subgroups split by the median of target gene expression: Patients with high expression and patients with low expression of the gene. In this project, patient data was evaluated in different subgroups referred to by histology, stage, grade, and various chemotherapy treatments.

The analysis of ovarian cancer patients was carried out for the enzymes HAS1, HAS2, HAS3, HYAL1, HYAL2, HYAL3, HYAL4, HYAL5 and HYALP1 of the hyaluronic system.

The Affymetrix ID for the genes are 207316_at for HAS1, 206432_at for HAS2, 223541_at for HAS3, 210619_s_at for HYAL1, 206855_s_at for HYAL2, 211728_s_at for HYAL3, 220249_at for HYAL4, 210536_s_at for HYAL5 and 1564777_at for HYALP1.

\section{Cell culture}

The human ovarian cancer cell line SKOV3 was purchased from ATCC/LGC Promochem (Wesel, Germany). Cells were cultured in McCoy's 5A medium (Sigma-Aldrich ${ }^{\circledR}$, prod. no. M9309, MDL no. MFCD00217560 Saint Louis, USA) containing 10\% fetal calf serum (FCS) (Pan biotech ${ }^{\mathrm{TM}}$, cat. no. P40-37500, Germany) and $1 \%$ Penicillin/Streptomycin (Sigma-Aldrich ${ }^{\circledR}$, cat. no. P4333, Saint Louis, USA) and were maintained in a humidified atmosphere with $7.5 \% \mathrm{CO}_{2}$ at $37^{\circ} \mathrm{C}$.

\section{SiRNA transfection}

$3,5 \times 10^{5}$ SKOV3 cells per well were cultured for 24 hours in McCoy's 5A medium containing $10 \%$ FCS and $1 \%$ Penicillin/Streptomycin. For transfection, the cells were 60-70\% confluent. First the medium was replaced by $840 \mu$ l Opti-MEM ${ }^{\circledR} /$ well $\left(\right.$ Gibco $^{\circledR}$, cat. no. 31985-070, Thermo-scientific, Germany). Cells in each well were transfected with $80 \mu 1$ 20nM negative control siRNA/Opti-MEM ${ }^{\circledR}$ (Ambion ${ }^{\circledR}$, cat. no. 4390844, Cambridgeshire, UK) or HAS2 siRNA/ Opti-MEM ${ }^{\circledR}\left(\right.$ Ambion $^{\circledR}$, cat. no. AM16708, ID 117327, Cambridgeshire, UK) and 80 $\mu 12,5 \%$ Lipofectamin/ Opti-MEM $^{\circledR}$ reagent (Lipofectamine ${ }^{\mathrm{TM}}$ RNAiMAX Transfection Reagent, cat. no. 13778-075, Thermo-scientific, Germany). Cells got in the incubator at $37^{\circ} \mathrm{C}$ and $7.5 \% \mathrm{CO}_{2}$. After 24 hours of incubation the transfection mixture was changed to 2ml/well McCoy's 5A medium containing $10 \%$ FCS and $1 \%$ Penicillin/Streptomycin.

\section{Quantitative real-time PCR}

The RNA of SKOV3 cells was isolated using the InnuPREP RNA mini kit (Analytikjena, cat. no. 845-KS-2040250, Jena, Germany). It was transcripted into cDNA carried out with the High-Capacity cDNA Reverse Transcription Kit (Applied Biosystems, cat. no. 4368814, Foster City, CA, USA) following the supplier's protocols.

Quantitative real-time PCR (qPCR) was performed in a 7300 real-time PCR detection system (Applied Biosystems) with RT2 SYBR Green qPCR Primer Assay (Qiagen, cat. no. 330500, Hilden, Germany) and Takyon ${ }^{\mathrm{TM}}$ ROX probe qPCR Kit (Eurogentec GmbH, cat. no. UF-RPMT-B0100, Cologne, Germany).

HAS2 knockdown was confirmed using the TaqMan probe HS00193435 m1 (Applied Biosystems). 
Results were evaluated using the $2^{-\Delta \Delta \mathrm{Ct}}$ method. Beta-actin samples were used as internal controls. The fold change shows the expression of the investigated enzymes in HAS2 knockdown cells compared to the control samples. Primer Sequences are shown in Supplementary table I. The results were formed out of 7 experiments with double or triple replicates in each experiment.

\section{Hanging drop assay}

The hanging drop method was used to measure cell cohesion and the ability to form spheroids of HAS2 knockdown cells compared to control cells. A $250 \mu \mathrm{l}$ solution consisting of medium and $2.5 \times 10^{5}$ SKOV3 cells was prepared. For each experiment, 12 drops with a volume of $20 \mu \mathrm{l}$ were placed on the inside of the lid of a Petri dish. $10 \mathrm{~mL}$ of sterile PBS were placed on the bottom of the Petri dish. Due to this the drops did not dry out. The Petri dish was placed in the incubator at $37^{\circ} \mathrm{C}$ and $7.5 \% \mathrm{CO}_{2}$. Pictures of the drops were taken with a ZEISS ${ }^{\circledR}$ Axiophot (Zeiss, Jena, Germany) bright-field microscope (magnification 5x) on day 4 and day 7 to visualize the form and size of the spheroids. This was done separately for control cells and HAS2 knockdown cells under the same conditions in four experiments with 12 drops each. Then, area and perimeter of the spheroids per drop were measured by using NIH ImageJ software (NIH, Bethesda, United States) ('Rasband, W.S., ImageJ, U. S. National Institutes of Health, Bethesda, Maryland, USA, https://imagej.nih.gov/ij/, 1997-2018.', retrieved 16.12.2021).

\section{MTT Assay}

In a 96-well plate, 2000 cells were added to each well with 200 $\mu 1$ DMEM Medium (Gibco ${ }^{\circledR}$, cat. no. 21063-029, ThermoFisher Scientific, Germany) containing $10 \%$ FCS. After 24 hours of incubation at $37^{\circ} \mathrm{C}$ and $7.5 \% \mathrm{CO}_{2}$ a defined amount of chemotherapy was given in every well. The various chemotherapeutic agents were added to the well rows in decreasing concentrations. The last well of each dilution series had a concentration of $0.00 \mathrm{nM}$ chemotherapy and served as a control. For Taxol, the first well had a concentration of $1000 \mathrm{nM}$. This was reduced to $0.941 \mathrm{nM}$ Taxol via a 11-part 1:2 dilution series. A dilution series was also applied for Cisplatin. The starting concentration was here $6.6656 \mathrm{nM}$ and the final concentration was $0.007 \mathrm{nM}$. For the combination of Taxol and Cisplatin, the starting concentration was $0.0429 \mathrm{nM}$ Taxol and $4.761 \mathrm{nM}$ Cisplatin. The final stage of the dilution series was $0.00004 \mathrm{nM}$ Taxol and $0.0046 \mathrm{nM}$ Cisplatin. After 72 hours incubation at $37^{\circ} \mathrm{C}$ and $7.5 \% \mathrm{CO}_{2}$ the medium was removed and cells were incubated for four hours with $20 \mu 1$ /well of 3-(4,5-Dimethylthiazol-2-yl)-2,5diphenyl-tetrazolium bromide at $5 \mathrm{mg} / \mathrm{ml}$. After that the reaction was stopped by adding $100 \mu 1$ Stopping solution/well. Stopping solution consisted of N,N-Dimethylformatid (Sigma-Aldrich ${ }^{\circledR}$, cat. no. 605365).

The absorbance was measured in a VersaMax ${ }^{\circledR}$ Microplate Reader (Molecular Devices, Sunnyvale, CA, USA) at a wavelength of $595 \mathrm{~nm}$. For data visualization, absorbances of all measured values were expressed as \%, with $100 \%$ corresponding to the measured absorbance of the control cells at $0.00 \mathrm{nM}$ chemotherapy. The results represent the values of three experiments performed in duplicates.

\section{STRING analysis}

STRING v11.5 (https://string-db.org, accessed on 02.09.2021) is an online bioinformatic tool to analyze in silico protein interaction networks (13). We carried out this analysis with the enzymes evaluated by the Kaplan-MeierPlotter analysis. STRING uses classification systems like Gene Ontology (GO) and Kyoto Encyclopedia of Genes and Genomes (KEGG). The interactions were predicted with a medium confidence threshold of 0.400 . All predictive methods were allowed. (Szklarczyk et al., 2019)

\section{Statistical analysis}

The statistical analysis of the Kaplan-Meier-Plotter was performed using the $\mathrm{R}$ statistical environment with the statistical package 'survival'. The Kaplan-Meier-Plotter showed the influence of different expression levels of enzymes on the chance of survival by using Kaplan-Meier survival curves, the Hazard Ratio and the corresponding p value. (Győrffy, Lánczky and Szállási, 2012), (Grillo, Győrffy and Götte, 2021) For qPCR, hanging drop and MTT Assay statistical analysis was performed using Microscoft Excel. Due to two-tailed t-test the $\mathrm{p}$ values were determined. $\mathrm{p} \leq 0.05$ is shown by $*, \mathrm{p} \leq 0.001$ by $* *$ and $\mathrm{p} \leq 0.0001$ by $* * *$.

\section{RESULTS}

\section{HAS2, HYAL2 and HYAL3 have a differential impact on the survival of ovarian cancer patients}

In this project, the Kaplan-Meier-Plotter database was used to present the influence of various enzymes of the hyaluronic acid system on the overall survival (OS) and the progression free survival (PFS) of patients. The number of specific patient cases per classification is shown in Table 1. The original patient collective was described in reference (Győrffy, Lánczky and Szállási, 2012). HAS2 had a significant negative impact on survival in terms of both, OS and PFS (Table 1, Figure 1 A, B). The HR (Hazard Ratio) of OS was 1.23 (p-value $=0.0019$ ) and the one of PFS was 1.14 ( $\mathrm{p}$-value $=0.042)$. A positive correlation was given to high expression of HYAL2 and HYAL3 
referred to PFS. The HR was 0.86 for both with a p-value of 0.023 for HYAL2 (Table 1, Figure 1 C) and 0.024 for HYAL3 (Table 1, Figure 1D).

Furthermore, subgroup analysis was done to find out whether enzymes had a particular stronger influence on certain patient groups. A distinction was made between histology, staging, grading and different chemotherapy approaches. Histology was subdivided into serous and endometrioid ovarian cancer, staging into stage I + II compared to III + IV and grading into grade I compared to II + III. The chemotherapy approaches were Taxol compared to Cisplatin and the combination of Taxol and Cisplatin. The results of these subgroup analysis are shown in Table 2 (HAS1-3), Table 3 (HYAL1-3) and Table 4 (HYAL4, HYAL5, HYALP1).

Table 2 shows that high expression of HAS1 $(\mathrm{HR}=1.3, \mathrm{p}$-value $=0.00033)$ had a negative impact on PFS for serous ovarian cancer patients. Furthermore, HAS2 had a negative correlation with the OS (HR $=1.26$, p-value $=$ $0.0027)$ and PFS $(\mathrm{HR}=1.31$, p-value $=0.00021)$. High expression of HYAL3 was correlated with a better OS $(\mathrm{HR}=0.83$, p-value $=0.016)$, which is shown in Table 3 . It is not possible to compute a Hazard Rate in case there is no event in one of the cohorts defined by the genes expression, as the HR will be either 0 or infinite in these cases. In such cases we adjusted the HR to $<0.1$. For patients with endometrioid ovarian cancer expression of HYAL2 $\left(\mathrm{HR}=0.17\right.$, p-value $\left.=5.00 * \mathrm{e}^{-4}\right)$ and HYAL5 $(\mathrm{HR}=0.3$, p-value $=0.015)$ was associated with better PFS (Table 3,4).

Referred to staging, no correlation of the hyaluronan-associated genes was found for patients in staging I+II (Table 2-4). High expression of HAS 1 ( $\mathrm{HR}=1.24$, p-value $=0.0033)$ was associated with worse PFS of patients in staging III + IV, as it is shown in Table 2. For staging III + IV HAS1 also correlated with worse OS $(\mathrm{HR}=1.18$, $\mathrm{p}$-value $=0.03)$ and PFS $(H R=1.2, \mathrm{p}$-value $=0.012)($ Table 2$)$. A positive influence on the OS had the expression of HYAL3 $(\mathrm{HR}=0.83$, p-value $=0.016)$ and HYAL4 $(\mathrm{HR}=0.85$, p-value $=0.035)$ as it is shown in Table 3 and 4.

For patients in grade I expression of HYAL2 $(\mathrm{HR}=0.18$, $\mathrm{p}$-value $=0.003)$ showed a positive impact on the OS (Table 3). No other correlations were found here. Referred to grading II+III there was a worse PFS for patients with high expression of HAS1 $(\mathrm{HR}=1.3$, p-value $=0.0003)$ and HAS2 $(\mathrm{HR}=1.26$, p-value $=0.0016)($ Table 2$)$. Furthermore HAS2 $(\mathrm{HR}=1.21$, p-value $=0.01)$ had a negative correlation with the OS. High expression of HYAL $3(\mathrm{HR}=0.83, \mathrm{p}$-value $=0.012)$ had a positive association with the OS of patients (Table 3$)$.

Finally, we analysed the prognostic impact of hyaluronan pathway constituents in patients stratified by different chemotherapy regimens. Table 2 shows that HAS2 $(\mathrm{HR}=1.27$, p-value $=0.0007)$ correlated with worse OS for patients treated with Platin chemotherapy. HYAL 3 was associated with better OS $(\mathrm{HR}=0.85, \mathrm{p}$-value $=0.02)$ and PFS $(\mathrm{HR}=0.8$, p-value $=0.0006)$ for these patients (Table 3$)$. In the patient subgroup treated with Taxol, the expression of HAS1 $(\mathrm{HR}=1.26$, p-value $=0.007)$ had a negative impact on the PFS of patients (Table 2). Also, the expression of HAS2 was associated with worse OS $(\mathrm{HR}=1.22$, $\mathrm{p}$-value $=0.041)$ and PFS $(\mathrm{HR}=1.23$, $\mathrm{p}$-value $=0.016$ ) for patients treated with Taxol (Table 2). The identical linkage was found with the combination therapy of Taxol + Cisplatin for the expression of HAS1 and PFS $(\mathrm{HR}=1.25$, p-value $=0.011)$ and HAS2 and OS $(\mathrm{HR}=$ $1.21, \mathrm{p}$-value $=0.045)$ and PFS $(\mathrm{HR}=1.23$, p-value $=0.019)($ Table 2$)$.

In conclusion, HAS2 appeared to be the enzyme of the hyaluronic acid system with the biggest impact on survival of ovarian cancer patients. Therefore, we decided to study the functional impact of HAS2 depletion using an in vitro siRNA approach in the human ovarian cancer cell line SKOV3.

\section{HAS2 depletion results in a moderate upregulation of HYAL3}

We first asked whether HAS2 knockdown affects the expression of other enzymes of the hyaluronic acid system. For this purpose, we used siRNA transfection and qPCR to detect the HAS2 knockdown and to compare the expression of HAS1, HAS3, HYAL2 and HYAL3 in HAS2 knockdown cells with the expression in control cells. These enzymes were chosen because they showed the greatest impact on patient survival in the Kaplan-MeierPlotter. It was shown that the knockdown of HAS2 worked. The p-value was $3.4866^{*} \mathrm{e}^{-9}$ for a mean fold change of 0.1792 and a standard error of 0.03 (Figure 2). This mean value was formed from $n=9$. In addition, no HAS2 expression was detectable in 6 values. These values were not included into the calculation.

The HAS2 knockdown did not have a significant influence on the expression of HAS1, HAS3 and HYAL2. HYAL3 was upregulated significantly with a mean value of 1.2381, a standard error of 0.0915 (p-value $=0.02$ ). Furthermore, the influence of HAS2 knockdown on the expression of HAS1, HAS3, HYAL2 and HYAL3 in cells treated with chemotherapy was investigated. A distinction was made between therapy with Taxol, Cisplatin and the combination of Taxol and Cisplatin. With all therapies, no significance was found with regard to the expression of HAS1, HAS3, HYAL2 and HYAL3. More detailed data are provided in the supplementary Figure S1. In 
conclusion, we could a successful HAS2 knockdown in SKOV3 cells. As a result, HYAL3 was moderately, yet significantly upregulated.

\section{HAS2 knockdown affects the formation of tumor cell spheroids}

Hyaluronic acid is an important factor that influences cell cohesion and stability. Moreover, a role for hyaluronan in cancer stem cell function has been described (D. Vitale et al., 2019). To test a possible influence of HAS2 knockdown on the capability of SKOV3 cells to form tumor spheroids, a hanging drop assay was performed. In the hanging drop method these factors were represented by the size of area and the perimeter of cell spheres in each drop. Differences were between control and HAS2 siRNA treated cells were analyzed regarding the area and perimeter of the spheres and area and perimeter of the spheres plus a diffuse edge/Margin that was visible under some of the treatment conditions. Spheroids of control cells and HAS2 knockdown cells on day 4 and day 7 are shown in Figure 3E.

We found that the area of spheres of HAS2 knockdown cells was significantly smaller on day $4(p$-value $=0.017)$ (Figure 3A). Furthermore, the perimeter of these was smaller for HAS2 knockdown cells compared to control cells on both days (day $4 \mathrm{p}$-value $=2.72 * \mathrm{e}^{-4}$, day $7 \mathrm{p}$-value $\left.=0.035\right)$ (Figure $\left.3 \mathrm{~B}\right)$. For values including the diffuse edge, the area of HAS2 knockdown cells was significantly higher on day 4 (p-value $=0.047$ ) and day 7 (p-value $=$ $4.965 * \mathrm{e}^{-10}$ ) (Figure 3C). Referred to the perimeter, measured values were significantly higher for HAS2 knockdown cells on day $7\left(\mathrm{p}\right.$-value $\left.=4.25^{*} \mathrm{e}^{-5}\right)($ Figure $3 \mathrm{D})$.

Beside this we observed that a diffuse edge was formed in $25 \%$ of the drops with control cells on day 4 and in $54 \%$ on day7 (Figure 3F). Compared to this HAS2 knockdown cells formed a diffuse edge in $76 \%$ of the drops on day 4 and $100 \%$ on day7 (Figure $3 \mathrm{~F}$ ). In the evaluation of the diffuse edge, only the drops that formed an edge were included. 2 drops of control cells on day 4 and 4 drops on day 7 did not form spheroids. HAS2 knockdown cells did not form a spheroid in 2 drops for both days. These samples were not included in the results. To conclude we found out that HAS2 knockdown cells formed significant smaller spheres with bigger edges, especially on day 7 . Furthermore, knockdown cells formed this edge more often.

\section{Impact of HAS2 siRNA depletion on cell viability and the response to chemotherapy}

As our Kaplan-Meier-Plotter analysed had indicated an impact of HAS2 on the prognosis of patients stratified by different chemotherapy regimen, we analysed the impact of HAS2-depletion in SKOV3 cells subjected to different forms of chemotherapy in vitro. The MTT Assay was used to assess whether the cell viability is influenced by HAS2 knockdown. In all chemotherapy treatment conditions, 11 serial 1:2 dilutions of Taxol, Cisplatin, and combinatorial treatment with both drugs was applied to control cells and HAS2 knockdown cells, with a specific start concentration per each chemotherapy approach (Figure 4).

Starting with the lowest concentration of chemotherapy all approaches had a concentration of $0.00 \mathrm{nM}$. The viability of HAS2 knockdown cells under these basal conditions was $46.68 \%$ lower compared to control cells (pvalue $=0.0002)$ (Figure $4 \mathrm{~A}-\mathrm{C})$. For Taxol the four lowest dilutions $(0.94 \mathrm{nM}-7.53 \mathrm{nM})$ showed significant results. For a treatment of $0.94 \mathrm{nM}$ Taxol the viability of HAS2 knockdown cells was 42,6\% lower compared to control cells ( $\mathrm{p}$-value $=0.0042$ ). At $1.8825 \mathrm{nM}$ Taxol HAS2 knockdown cells had a $50.66 \%$ smaller viability (pvalue $=0.0068)$. The viability of HAS2 knockdown cells was $34.12 \%$ lower at $3.765 \mathrm{nM}$ Taxol $(\mathrm{p}$-value $=0.0221)$ and $33.46 \%$ lower at $7.53 \mathrm{nM}$ (p-value $=0.0193$ ). For concentrations of $15.06 \mathrm{nM}$ to $250 \mathrm{nM}$ no significant values were measured. At $500 \mathrm{nM}$ Taxol HAS2 knockdown cells had a $36.04 \%$ lower viability (p-value $=0.0228$ ). For a concentration of $1000 \mathrm{nM}$ no significance was found. (Figure 4A) Treatment of Cisplatin did not show significant values for concentrations of $0.0065 \mathrm{nM}$ to $0.104 \mathrm{nM}$. HAS2 knockdown cells treated with $0.2083 \mathrm{nM}$ Cisplatin showed a $29.35 \%$ lower viability than control cells ( $\mathrm{p}$-value $=0.0437)$. Concentrations of $0.416 \mathrm{nM}$ to $6.665 \mathrm{nM}$ did not show significant values (Figure 4B). A significant value was measured at $0.00067 \mathrm{nM}$ Taxol and 0.0744 $\mathrm{nM}$ Cisplatin for the combination of Taxol + Cisplatin. The viability of HAS2 knockdown cells was $38.7 \%$ smaller $(\mathrm{p}$-value $=0.022)($ Figure $4 \mathrm{C})$. All in all, the viability of HAS2 knockdown cells was lower than control cells, indicating that the impact of HAS2 depletion alone on cell viability was higher than a possible effect of HAS2 on the chemotherapy response under our assay conditions.

String analysis reveals interconnection of the hyaluronan system and pathogenetic factors in ovarian cancer Our last step of analysis was the use of the STRING tool to show interactions of HAS1-3 (Fig. 5A) and HYAL15 (Fig. 5B) between each other and the 10 closest interactions with other proteins. For each protein the interactions were analyzed related to gene neighborhood, gene fusions, gene co-occurrence, experimentally determination, curated databases, co-expression, protein homology and text mining. HYALP1 was not analyzed by the STRING tool. Referred to the hyaluronan system it was shown that there is high interaction between HAS2 and HAS3. 
HAS1-3 interacted with SPAM1 due to co expression and text mining. Text mining indicated an interaction between HAS1-3 and HYAL2 and HYAL3 and between HAS2 and HYAL4 (Figure 5A\&B).

Related to other proteins HAS1-3 showed high interaction with UGDH, CD44 and HMMR. Beside this HAS1 and 2 cooperated with VCAN. Interactions of the hyaluronic synthases in form of text mining were given with PTX3, TNFAIP6 and HABPS. (Figure 5A) UGDH plays a role in glycosaminoglycan synthesis and therefore is also important in relation to extracellular matrix and synthesis of hyaluronan. (Egger et al., 2011) CD44 is a non-kinase transmembrane proteoglycan, which mainly ligand is hyaluronan. The hyaluronan mediated motility receptor (HMMR or RHAMM) also has hyaluronan as its main ligand. The binding of hyaluronan to CD44 or RHAMM allows intracellular adapter molecules to bind. This promotes cell adhesion, cell migration and cell proliferation. (Chen et al., 2018),(Savani et al., 2001) VCAN is a proteoglycan in the extracellular matrix. It supports growth, survival, angiogenesis, metastasis, migration and invasion of tumor cells.(Li et al., 2020),(Fujii et al., 2015) The pentraxin PTX3 is an important component of the innate immune response and binds to microbial moieties. Furthermore it interacts with TSG-6 and I $\alpha$ I, which are proteins of the extracellular matrix.(Bottazzi et al., 2010) TNFAIP6 is a hyaluronan-binding protein that improves extracellular matrix stability and cell migration. It also enhances the effect of IaI. (TNFAIP6 Gene - GeneCards | TSG6 Protein | TSG6 Antibody, no date) HABPs are high-active binding peptides that have high specific host cell binding activity. (Curtidor et al., 2011)

Hyaluronidases collaborated with ARSB, IDUA and GUSB mainly in the form of protein homology and text mining. A high interaction was found between HYAL2 and CD44, HMMR, MST1R and WWOX. SPAM1 showed high interaction with ADAM2. Text mining was given between hyaluronidases and HMMR, MST1R and CD44. (Figure 5B) ARSB is responsible for the degradation of mucopolysaccharides in lysosomes, including the degradation of glycosaminoglycans.(Tomanin et al., 2018) IDUA is also a lysosomal enzyme that degrades the glycosaminoglycans heparin sulphate and dermatan sulphate.(Gul et al., 2020) GUSB also degrades glycosaminoglycans in lysosomes. Examples are heparan sulfate, dermatan sulfate and chondroitin-4,6sulfate.(Tomatsu et al., 2009) Macrophage stimulating 1-receptor (MST1R) is a receptor tyrosin kinase which can be find in epithelial cells and terminally-differentiated macrophages. Its role is to form extracellular into intracellular signals. (Wagh, Peace and Waltz, 2008) WWOX is a tumor suppressor and indicates apoptosis due to transducing signals of protein/protein interactions.(Liu et al., 2018) ADAM2 is produced in testis and can be found as a membrane protein at the surface of sperms.(Choi et al., 2016)

\section{DISCUSSION}

In this study, we addressed the question if the level of expression of HAS1-3, HYAL1-5 and HYALP1 has an influence on the survival of ovarian cancer patients. We hypothesized that the expression of HAS2 could have an effect on the success of therapy and sphere formation capability and cohesion of the tumor cells.

\section{Influence of hyaluronan synthases HAS1-3 on ovarian cancer and patient's survival}

First, we compared the survival time of patients with low expression of the enzymes with those with high expression by the use of the Kaplan-Meier Plotter (https://kmplot.com/analysis/). The protein interactions between each other and with other enzymes were visualized by using the STRING tool (https://string-db.org). We could show that especially HAS1 and HAS2 expression correlated with worse survival of ovarian cancer patients (Table 1-4). In some subgroups, the data have to be interpreted with caution, especially when the number of cases was below 50. This applies for HAS1 and HAS2 to data of OS of patients with endometrioid ovarian cancer and of PFS of patients in grading 1. For HAS3 it concerns OS and PFS of patients with endometrioid ovarian cancer and OS and PFS of patients in grading I. Due to the small number of cases, false tendencies could arise.

In our study we showed with qPCR that the expression of HAS1 is not influenced by downregulation of HAS2. The influence of HAS1 on the survival of ovarian cancer patients has not yet been studied in detail. However, it has been shown that high HAS1 expression is associated with poor patient survival for ovarian cancer, colon cancer, Waldenström's macroglobulinemia and the multiple myeloma. (Siiskonen et al., 2015, p. 1) This fits to our result for ovarian cancer that we have found in our project using the Kaplan Meier Plotter. In addition it is known that downregulation of HAS1 expression correlates with lower growth and development of bladder cancer due to lower hyaluronan production.(Golshani et al., 2008) This also fits with our findings from the Kaplan-Meier-Plotter that high HAS1 expression leads to lower survival. One assumption is that high HAS1 expression ends in higher hyaluronan production. This could lead to greater tumor growth. This has already been shown for the ability of prostate cancer to metastasise to the bone marrow (Simpson et al., 2002)(Simpson et al., 2001).

Referred to HAS2 we performed a HAS2 knockdown by using siRNA transfection after we showed the significant role of HAS2 due to the Kaplan Meier Plotter. By the use of qPCR, we proved that the knockdown worked (Figure 2). We examined the influence of HAS2 in more detail by comparing HAS2 knockdown cells 
with control cells. This was carried out in relation to the expression of HAS1, HAS3 and HYAL2 and HYAL3 using qPCR and the ability of cell cohesion by the use of the hanging drop method was examined. The cell viability was measured during treatment with different concentrations of chemotherapy by MTT Assay.

Referred to the Kaplan Meier Plotter it was found, in agreement with our result for ovarian cancer, that high HAS2 expression also leads to short OS of pancreatic cancer patients. (Yu et al., 2021) In addition to that it has been reported that higher HAS2 expression can be found in breast cancer cell lines compared to normal breast tissue. Furthermore it was proven in this study that HAS2 knockdown cell lines had lower proliferation and more apoptosis compared to breast cancer cells without knockdown.(Li et al., no date) A correlation between high coexpression of HAS2 and HYAL1 and strong tumor growth and angiogenesis was observed for prostate carcinoma. (Simpson, 2006)

Subsequently, using the hanging drop method, we observed significantly poorer cell cohesion in HAS2 knockdown cells (Figure 3). This could be due to a lack of HA synthesis as a result of the knockdown. This hypothesis is supported by another study which observed that high expression of hyaluronan synthase and hyaluronan correlates with higher metastasation and invasiveness for different tumor types. (Jojovic et al., 2002) Furthermore, it has also been shown for ovarian clear cell carcinomas that tumor cell growth is inhibited by low levels of hyaluronic acid. (Kato et al., 2016)

These facts support our hanging drop results and hypothesis that HAS2 is necessary for better cell growth and migration. We found significantly reduced cell viability in HAS2 knockdown cells by MTT assay, even without prior chemotherapy treatment. This could be an indication that the cells grow worse due to lack of HA production (Figure 4). This also fits with the statements of Okuda and colleagues that high HAS2 expression in breast cancer cells correlates with increased growth and metastasis than control cells. Furthermore, it indicates a lower overall survival time of patients. (Okuda et al., 2012) This matches with our results of the Kaplan Meier Plotter for ovarian cancer patients.

The control and HAS2 knockdown cells showed a moderate response to the different chemotherapy treatments (Figure 4).

The therapeutic effect of chemotherapy for ovarian cancer can low be low due to chemotherapy resistance (Ricciardelli, C. et al. 2013). We could show that this is not significantly changed by HAS2 knockdown, but the viability of HAS2 knockdown cells is fundamentally poorer. Indeed, Wang et al showed that the effectiveness of chemotherapy can be improved, for example for Paclitaxel through a hyaluronic acid-based nano system. (Wang and Jia, 2016) Furthermore, Lokman et al were able to show that a more successful therapy of chemotherapyresistant serous ovarian cancer cells seems to be possible through the combination of Carboplatin and 4Methylumbelliferone. This inhibits hyaluronic acid production, cell survival and spheroid formation in these cells. This is therapeutically significant, as increased HAS2 and HAS3 expression was observed in chemotherapy resistant ovarian cancer cells. (Lokman et al., 2019) In addition, Bourguignon et al showed that chemotherapy resistance in ovarian and breast cancer cells arises via the hyaluronan acid - CD44 interaction by inducing the binding of Ankyrin to MDR1. (Bourguignon et al., 2008, p. 44)

Ricciardelli et al also showed that the hyaluronic acid - CD44 signaling pathway could be an important approach for treating development of resistance to carboplatin in ovarian cancer patients. Indeed, after carboplatin treatment, the expression of HAS2, HAS3, ABCC2 and HA secretion increased. A high HA-level in turn correlated with a higher survival of CD44 positive ovarian cancer cells. Hyaluronic acid thus appears to be a relevant factor in relation to the high survival of tumor cells after carboplatin treatment. (Ricciardelli et al., 2013) In order to be able to treat ovarian cancer optimally, further research is needed in this area.

The fact that low expression of HAS2 is correlated with lower tumor cell growth is strengthened by the results of String analysis that HAS1-3 interact close with UGDH that indicates glycosaminoglycan synthesis (Egger et al., 2011), and CD44 and RHAMM, which functions are supporting cell adhesion, cell migration and cell proliferation (Chen et al., 2018) (Savani et al., 2001).

For HAS3 we did not found significant correlation between its expression and patient survival. Furthermore, there was no significant connection between HAS2 knockdown and HAS3 expression although the string analysis showed a strong correlation (Figure 5A). In summary, HAS3 did not appear to play a central role in the survival of ovarian cancer patients in our study.

In a study of 2003, it was found that HAS3 is overexpressed in metastatic tissue of colon carcinoma.

Furthermore HAS3 knockdown colon cancer cells showed an inhibition in growth. (Bullard et al., 2003) The same influence of HAS3 knockdown is also known for oesophageal squamous cell carcinoma. (Twarock et al., 2011) Nevertheless we did not found significant results for ovarian cancer. 
Overall, our results and already known publications indicate that increased HAS synthesis and consequently increased HA production led to increased tumor cell growth and reduced survival time, respectively.

In contrast to this is the observation that high hyaluronan production is associated with lower adhesion to the peritoneum in ovarian cancer cells and therefore seems to be protective with respect to metastasis to the peritoneum. (Tamada et al., 2012) Furthermore, hyaluronan could also be used in tumor therapy for ovarian cancer patients in the form of cross-linked hyaluronan gel. This gel seems to stop further tumor growth by inhibiting the migration and proliferation of cells, as well as reducing the occurrence of adhesions. (Pang et al., 2018) With regard to patients with chemotherapy-induced primary ovarian insufficiency (POI), it has been shown in experiments with rats that hyaluronic acid appears to have a preventive effect in these patients due to the promotion of granulosa cells and upregulation of PGRMC1 expression. (Zhao et al., 2015) These results show that hyaluronan seems to have both, positive and negative effects on ovarian cancer progression and ovarian diseases.

\section{Influence of hyaluronidases HYAL1-5 and HYALP1 on ovarian cancer and the patient's survival}

With the use of the Kaplan-Meier-Plotter we could show that patients with high HYAL2 and HYAL3 expression had a better survival. HYAL4 had a positive influence for patients in staging III + IV for OS and HYAL5 for patients with an endometrioid carcinoma for PFS. Referred to HYAL1 and HYALP1 no correlation was found (Table 1-4).

In agreement with that it has been reported that HYAL1 is upregulated in clear cell and mucinous ovarian cancer cells, but not in serous and endometrioid ones. (Yoffou et al., 2011) Nevertheless, another group found significant lower levels of HYAL1 in serous ovarian cancer cells. They did not found a changed regulation of HAS1-3. (Nykopp et al., 2009) With regard to the hyaluronidases, we found most significances for HYAL2 and HYAL3. Therefore, only these two hyaluronidases were included in the more detailed laboratory investigation. With qPCR it was shown that HAS2 knockdown leads to a significant upregulation of HYAL3 with a fold of 1.2381. HYAL2 did not show a significant correlation (Figure 2). Therefore, there could be a connection or counter-regulation between HAS2 and HYAL3. Until then, no significant correlation was found in previous studies.

In contrast to our qPCR results it was reported for breast cancer that HAS2 knockdown in Hs578T cancer cells lead to an upregulation of HAS1, HAS3 and HYAL1. Furthermore produced hyaluronan was smaller and the migration of cancer cells was slower. (Li et al., 2007) Beside this, it has been reported that HAS2 knockdown in breast cancer cells lead to a downregulation of HYAL2 and CD44. (Udabage et al., 2005) One possibility for a optimized future therapy of ovarian cancer could be the treatment with Irinotecan conjugated to hyaluronan, which has been tested in mice. This could make a regionally specified therapy on ovarian cancer cells possible. (Montagner et al., 2015)

\section{Conclusions}

In summary, HAS2 may be an important prognostic factor in ovarian cancer. We could show that HAS2 expression correlates with higher tumor cell growth and viability and lower survival. A low HAS1 and HAS2 level is associated with better patients' survival. This also applies to high expression of HYAL2 and HYAL3. Nevertheless, further research is needed on the relevance of the hyaluronic acid system in ovarian cancer. In particular, an optimization of the therapy treatment is a central research goal. In this respect, HAS2 does not seem to play a central role with regard to the sensitivity of ovarian cancer cells to the chemotherapies Taxol and Cisplatin. In addition, it could be researched more closely, if the possible connection between the expression of HAS2 and HYAL3 has a consequence for example for hyaluronan production or tumor cell behaviour. 


\section{LITERATURE}

Bottazzi, B. et al. (2010) 'An Integrated View of Humoral Innate Immunity: Pentraxins as a Paradigm', Annual Review of Immunology, 28(1), pp. 157-183. doi:10.1146/annurev-immunol-030409-101305.

Bourguignon, L.Y.W. et al. (2008) 'Hyaluronan-CD44 Interaction Activates Stem Cell Marker Nanog, Stat-3mediated MDR1 Gene Expression, and Ankyrin-regulated Multidrug Efflux in Breast and Ovarian Tumor Cells’, Journal of Biological Chemistry, 283(25), pp. 17635-17651. doi:10.1074/jbc.M800109200.

Bullard, K.M. et al. (2003) 'Hyaluronan synthase-3 is upregulated in metastatic colon carcinoma cells and manipulation of expression alters matrix retention and cellular growth', International Journal of Cancer, 107(5), pp. 739-746. doi:10.1002/ijc.11475.

Caon, I. et al. (2021) 'Cell Energy Metabolism and Hyaluronan Synthesis', Journal of Histochemistry \& Cytochemistry, 69(1), pp. 35-47. doi:10.1369/0022155420929772.

Chen, C. et al. (2018) 'The biology and role of CD44 in cancer progression: therapeutic implications', Journal of Hematology \& Oncology, 11(1), p. 64. doi:10.1186/s13045-018-0605-5.

Choi, H. et al. (2016) 'Characterization of Mammalian ADAM2 and Its Absence from Human Sperm', PLOS ONE. Edited by A.C. Gill, 11(6), p. e0158321. doi:10.1371/journal.pone.0158321.

Curtidor, H. et al. (2011) 'Functional, Immunological and Three-Dimensional Analysis of Chemically Synthesised Sporozoite Peptides as Components of a Fully-Effective Antimalarial Vaccine', Current Medicinal Chemistry, 18(29), pp. 4470-4502. doi:10.2174/092986711797287575.

Egger, S. et al. (2011) 'Structure and Mechanism of Human UDP-glucose 6-Dehydrogenase', Journal of Biological Chemistry, 286(27), pp. 23877-23887. doi:10.1074/jbc.M111.234682.

Fujii, K. et al. (2015) 'Versican upregulation in Sézary cells alters growth, motility and resistance to chemotherapy’, Leukemia, 29(10), pp. 2024-2032. doi:10.1038/leu.2015.103.

Garantziotis, S. and Savani, R.C. (2019) 'Hyaluronan biology: A complex balancing act of structure, function, location and context', Matrix Biology, 78-79, pp. 1-10. doi:10.1016/j.matbio.2019.02.002.

Golshani, R. et al. (2008) 'Hyaluronic Acid Synthase-1 Expression Regulates Bladder Cancer Growth, Invasion, and Angiogenesis through CD44', Cancer Research, 68(2), pp. 483-491. doi:10.1158/0008-5472.CAN-07-2140.

Grillo, P.K., Győrffy, B. and Götte, M. (2021) 'Prognostic impact of the glypican family of heparan sulfate proteoglycans on the survival of breast cancer patients', Journal of Cancer Research and Clinical Oncology, 147(7), pp. 1937-1955. doi:10.1007/s00432-021-03597-4.

Gul, R. et al. (2020) 'IDUA gene mutations in mucopolysaccharidosis type-1 patients from two Pakistani inbred families’, Congenital Anomalies, 60(4), pp. 126-127. doi:10.1111/cga.12354.

Győrffy, B., Lánczky, A. and Szállási, Z. (2012) 'Implementing an online tool for genome-wide validation of survival-associated biomarkers in ovarian-cancer using microarray data from 1287 patients', Endocrine-Related Cancer, 19(2), pp. 197-208. doi:10.1530/ERC-11-0329.

Hemming, R. et al. (2008) 'Mouse Hyal3 encodes a 45- to 56-kDa glycoprotein whose overexpression increases hyaluronidase 1 activity in cultured cells', Glycobiology, 18(4), pp. 280-289. doi:10.1093/glycob/cwn006.

Jojovic, M. et al. (2002) 'Expression of hyaluronate and hyaluronate synthase in human primary tumours and their metastases in scid mice', Cancer Letters, 188(1-2), pp. 181-189. doi:10.1016/S0304-3835(02)00037-X.

Kaneiwa, T. et al. (2010) 'Identification of human hyaluronidase-4 as a novel chondroitin sulfate hydrolase that preferentially cleaves the galactosaminidic linkage in the trisulfated tetrasaccharide sequence', Glycobiology, 20(3), pp. 300-309. doi:10.1093/glycob/cwp174. 
Kato, N. et al. (2016) 'Relation between hyaluronan synthesis and cell morphology in ovarian clear cell carcinomas: Hyaluronan in clear cell carcinoma', Pathology International, 66(4), pp. 218-223. doi:10.1111/pin.12405.

Li, P. et al. (no date) 'Hyaluronan synthase 2 overexpression is correlated with the tumorigenesis and metastasis of human breast cancer', p. 14.

Li, W. et al. (2020) 'High expression of VCAN is an independent predictor of poor prognosis in gastric cancer', Journal of International Medical Research, 48(1), p. 030006051989127. doi:10.1177/0300060519891271.

Li, Y. et al. (2007) 'Silencing of hyaluronan synthase 2 suppresses the malignant phenotype of invasive breast cancer cells', International Journal of Cancer, 120(12), pp. 2557-2567. doi:10.1002/ijc.22550.

Liu, C.-C. et al. (2018) 'WWOX Phosphorylation, Signaling, and Role in Neurodegeneration', Frontiers in Neuroscience, 12, p. 563. doi:10.3389/fnins.2018.00563.

Lokman, N.A. et al. (2019) '4-Methylumbelliferone Inhibits Cancer Stem Cell Activation and Overcomes Chemoresistance in Ovarian Cancer', Cancers, 11(8), p. 1187. doi:10.3390/cancers11081187.

Matsumoto, K. et al. (2009) 'Conditional inactivation of Has2 reveals a crucial role for hyaluronan in skeletal growth, patterning, chondrocyte maturation and joint formation in the developing limb', Development, 136(16), pp. 2825-2835. doi:10.1242/dev.038505.

Miller, K.A., Shao, M. and Martin-Deleon, P.A. (2006) 'Hyalp1 in Murine Sperm Function: Evidence for Unique and Overlapping Functions With Other Reproductive Hyaluronidases', Journal of Andrology, 28(1), pp. 67-76. doi:10.2164/jandrol.106.000356.

Montagner, I.M. et al. (2015) 'Drug conjugation to hyaluronan widens therapeutic indications for ovarian cancer', Oncoscience, 2(4), pp. 373-381. doi:10.18632/oncoscience.150.

Nykopp, T.K. et al. (2009) 'Expression of Hyaluronan Synthases (HAS1-3) and Hyaluronidases (HYAL1-2) in Serous Ovarian Carcinomas: Inverse Correlation between HYAL1 and Hyaluronan Content', BMC Cancer, 9(1), p. 143. doi:10.1186/1471-2407-9-143.

Okuda, H. et al. (2012) 'Hyaluronan Synthase HAS2 Promotes Tumor Progression in Bone by Stimulating the Interaction of Breast Cancer Stem-Like Cells with Macrophages and Stromal Cells', Cancer Research, 72(2), pp. 537-547. doi:10.1158/0008-5472.CAN-11-1678.

Pang, J. et al. (2018) 'Cross-linked hyaluronan gel inhibits the growth and metastasis of ovarian carcinoma', Journal of Ovarian Research, 11(1), p. 22. doi:10.1186/s13048-018-0394-z.

'Rasband, W.S., ImageJ, U. S. National Institutes of Health, Bethesda, Maryland, USA, https://imagej.nih.gov/ij/, 1997-2018.' (no date).

Ricciardelli, C. et al. (2013) 'Chemotherapy-induced hyaluronan production: a novel chemoresistance mechanism in ovarian cancer', BMC Cancer, 13(1), p. 476. doi:10.1186/1471-2407-13-476.

Savani, R.C. et al. (2001) 'Differential Involvement of the Hyaluronan (HA) Receptors CD44 and Receptor for HA-mediated Motility in Endothelial Cell Function and Angiogenesis', Journal of Biological Chemistry, 276(39), pp. 36770-36778. doi:10.1074/jbc.M102273200.

Siiskonen, H. et al. (2015) 'Hyaluronan Synthase 1: A Mysterious Enzyme with Unexpected Functions', Frontiers in Immunology, 6. doi:10.3389/fimmu.2015.00043.

Simpson, M.A. et al. (2001) 'Hyaluronan Synthase Elevation in Metastatic Prostate Carcinoma Cells Correlates with Hyaluronan Surface Retention, a Prerequisite for Rapid Adhesion to Bone Marrow Endothelial Cells', Journal of Biological Chemistry, 276(21), pp. 17949-17957. doi:10.1074/jbc.M010064200.

Simpson, M.A. et al. (2002) 'Manipulation of Hyaluronan Synthase Expression in Prostate Adenocarcinoma Cells Alters Pericellular Matrix Retention and Adhesion to Bone Marrow Endothelial Cells', Journal of Biological Chemistry, 277(12), pp. 10050-10057. doi:10.1074/jbc.M110069200. 
Simpson, M.A. (2006) 'Concurrent Expression of Hyaluronan Biosynthetic and Processing Enzymes Promotes Growth and Vascularization of Prostate Tumors in Mice', The American Journal of Pathology, 169(1), pp. 247257. doi:10.2353/ajpath.2006.060032.

Szklarczyk, D. et al. (2019) 'STRING v11: protein-protein association networks with increased coverage, supporting functional discovery in genome-wide experimental datasets', Nucleic Acids Research, 47(D1), pp. D607-D613. doi:10.1093/nar/gky1131.

Tamada, Y. et al. (2012) 'Cell surface expression of hyaluronan on human ovarian cancer cells inversely correlates with their adhesion to peritoneal mesothelial cells', Tumor Biology, 33(4), pp. 1215-1222. doi:10.1007/s13277-012-0369-4.

Tammi, R.H. et al. (2008) 'Hyaluronan in human tumors: Pathobiological and prognostic messages from cellassociated and stromal hyaluronan', Seminars in Cancer Biology, 18(4), pp. 288-295. doi:10.1016/j.semcancer.2008.03.005.

Tavianatou, A.G. et al. (2019) 'Hyaluronan: molecular size-dependent signaling and biological functions in inflammation and cancer', The FEBS Journal, 286(15), pp. 2883-2908. doi:10.1111/febs.14777.

TNFAIP6 Gene - GeneCards | TSG6 Protein | TSG6 Antibody (no date). Available at: https://www.genecards.org/cgi-bin/carddisp.pl?gene=TNFAIP6 (Accessed: 4 September 2021).

Tomanin, R. et al. (2018) 'Mucopolysaccharidosis type VI (MPS VI) and molecular analysis: Review and classification of published variants in the ARSB gene', Human Mutation, 39(12), pp. 1788-1802. doi:10.1002/humu.23613.

Tomatsu, S. et al. (2009) 'Mutations and polymorphisms in GUSB gene in mucopolysaccharidosis VII (Sly Syndrome)', Human Mutation, 30(4), pp. 511-519. doi:10.1002/humu.20828.

Triggs-Raine, B. (2015) 'Biology of hyaluronan: Insights from genetic disorders of hyaluronan metabolism', World Journal of Biological Chemistry, 6(3), p. 110. doi:10.4331/wjbc.v6.i3.110.

Twarock, S. et al. (2011) 'Inhibition of Oesophageal Squamous Cell Carcinoma Progression by in vivo Targeting of Hyaluronan Synthesis', Molecular Cancer, 10(1), p. 30. doi:10.1186/1476-4598-10-30.

Udabage, L. et al. (2005) 'Antisense-Mediated Suppression of Hyaluronan Synthase 2 Inhibits the Tumorigenesis and Progression of Breast Cancer', Cancer Research, 65(14), pp. 6139-6150. doi:10.1158/00085472.CAN-04-1622.

Vitale, D. et al. (2019) 'Proteoglycans and glycosaminoglycans as regulators of cancer stem cell function and therapeutic resistance', The FEBS Journal, 286(15), pp. 2870-2882. doi:10.1111/febs.14967.

Vitale, S.G. et al. (2019) 'Management of endometrial, ovarian and cervical cancer in the elderly: current approach to a challenging condition', Archives of Gynecology and Obstetrics, 299(2), pp. 299-315. doi:10.1007/s00404-018-5006-Z.

Wagh, P.K., Peace, B.E. and Waltz, S.E. (2008) 'Met-Related Receptor Tyrosine Kinase Ron in Tumor Growth and Metastasis', in Advances in Cancer Research. Elsevier, pp. 1-33. doi:10.1016/S0065-230X(08)00001-8.

Wagner, U. and Reuß, A. (2019) 'S3-Leitlinie „Diagnostik, Therapie und Nachsorge maligner Ovarialtumoren“: Leitlinienprogramm Onkologie, Deutsche Krebsgesellschaft, Deutsche Krebshilfe, AWMF: Langversion 3.0, 2019, AWMF-Registernummer: 032/035OL', Forum, 34(5), pp. 413-415. doi:10.1007/s12312-019-00671-4.

Wang, L. and Jia, E. (2016) 'Ovarian cancer targeted hyaluronic acid-based nanoparticle system for paclitaxel delivery to overcome drug resistance', Drug Delivery, 23(5), pp. 1810-1817. doi:10.3109/10717544.2015.1101792.

Ween, M., Oehler, M. and Ricciardelli, C. (2011) 'Role of Versican, Hyaluronan and CD44 in Ovarian Cancer Metastasis', International Journal of Molecular Sciences, 12(2), pp. 1009-1029. doi:10.3390/ijms12021009. 
Weiss, I. et al. (2012) 'Hyaluronan Synthase and Hyaluronidase Expression in Serous Ovarian Carcinoma is Related to Anatomic Site and Chemotherapy Exposure', International Journal of Molecular Sciences, 13(12), pp. 12925-12938. doi:10.3390/ijms131012925.

WHO, international Agency for Research on Cancer, CANCER TODAY (https://gco.iarc.fr/today/home, retrieved on 16.12.2021) 'Estimated age-standardized incidence and mortality rates (World) in 2020, worldwide, both sexes, all ages'.

Yabushita, H. et al. (2004) 'Hyaluronan synthase expression in ovarian cancer', Oncology Reports [Preprint]. doi:10.3892/or.12.4.739.

Yamaguchi, Y. et al. (2019) 'TMEM2: A missing link in hyaluronan catabolism identified?', Matrix Biology, 78-79, pp. 139-146. doi:10.1016/j.matbio.2018.03.020.

Yoffou, P.H. et al. (2011) 'Subtype Specific Elevated Expression of Hyaluronidase-1 (HYAL-1) in Epithelial Ovarian Cancer', PLoS ONE. Edited by N.S. Wong, 6(6), p. e20705. doi:10.1371/journal.pone.0020705.

Yu, M. et al. (2021) 'Increased SPHK1 and HAS2 Expressions Correlate to Poor Prognosis in Pancreatic Cancer’, BioMed Research International. Edited by M.I. Bellini, 2021, pp. 1-8. doi:10.1155/2021/8861766.

Zhao, G. et al. (2015) 'Hyaluronic acid prevents immunosuppressive drug-induced ovarian damage via upregulating PGRMC1 expression', Scientific Reports, 5(1), p. 7647. doi:10.1038/srep07647.

\section{STATEMENTS AND DECLARATIONS}

\section{Funding}

Open Access funding enabled and organized by Projekt DEAL. The research was financed by the 2018-2.1.17TET-KR-00001 grant and by the Higher Education Institutional Excellence Programme (2020-4.1.1.-TKP2020) of the Ministry for Innovation and Technology in Hungary (to BG), by the Open Access Publishing Fonds of the WWU Münster, and by EU H2020 MSCA RISE project \#645756 GLYCANC (to MG, AP).

\section{Competing interests}

The authors have no relevant financial or non-financial interests to disclose.

\section{Author contributions}

J.R. performed the Kaplan-Meier and STRING analyses and all in vitro experiments, and wrote the original manuscript draft. BG provided essential resources and supervised and supported the Kaplan-Meier analysis. L.K. provided clinical expertise and ressources. A.P. and D.V. provided expertise on hyaluronan and advice on the design and interpretation of experiments. M.G. conceived, coordinated and supervised the study. All authors revised the manuscript draft.

\section{Availability of data and material}

The datasets generated and analysed during the first part of the current study, the survival analysis, are available in the Kaplan-Meier Plotter database https://kmplot.com/analysis/. The datasets generated and analysed during the second part of the current study, the cell line data, are available from the corresponding author on reasonable request.

\section{Open Access}

This article is licensed under a Creative Commons Attribution 4.0 International License, which permits use, sharing, adaptation, distribution and reproduction in any medium or format, as long as you give appropriate credit to the original author(s) and the source, provide a link to the Creative Commons licence, and indicate if changes were made. The images or other third party material in this article are included in the article's Creative Commons licence, unless indicated otherwise in a credit line to the material. If material is not included in the article's Creative Commons licence and your intended use is not permitted by statutory regulation or exceeds the permitted use, you will need to obtain permission directly from the copyright holder. To view a copy of this licence, visit http://creativecommons.org/licenses/by/4.0/. 


\section{FIGURE LEGENDS AND TABLES:}
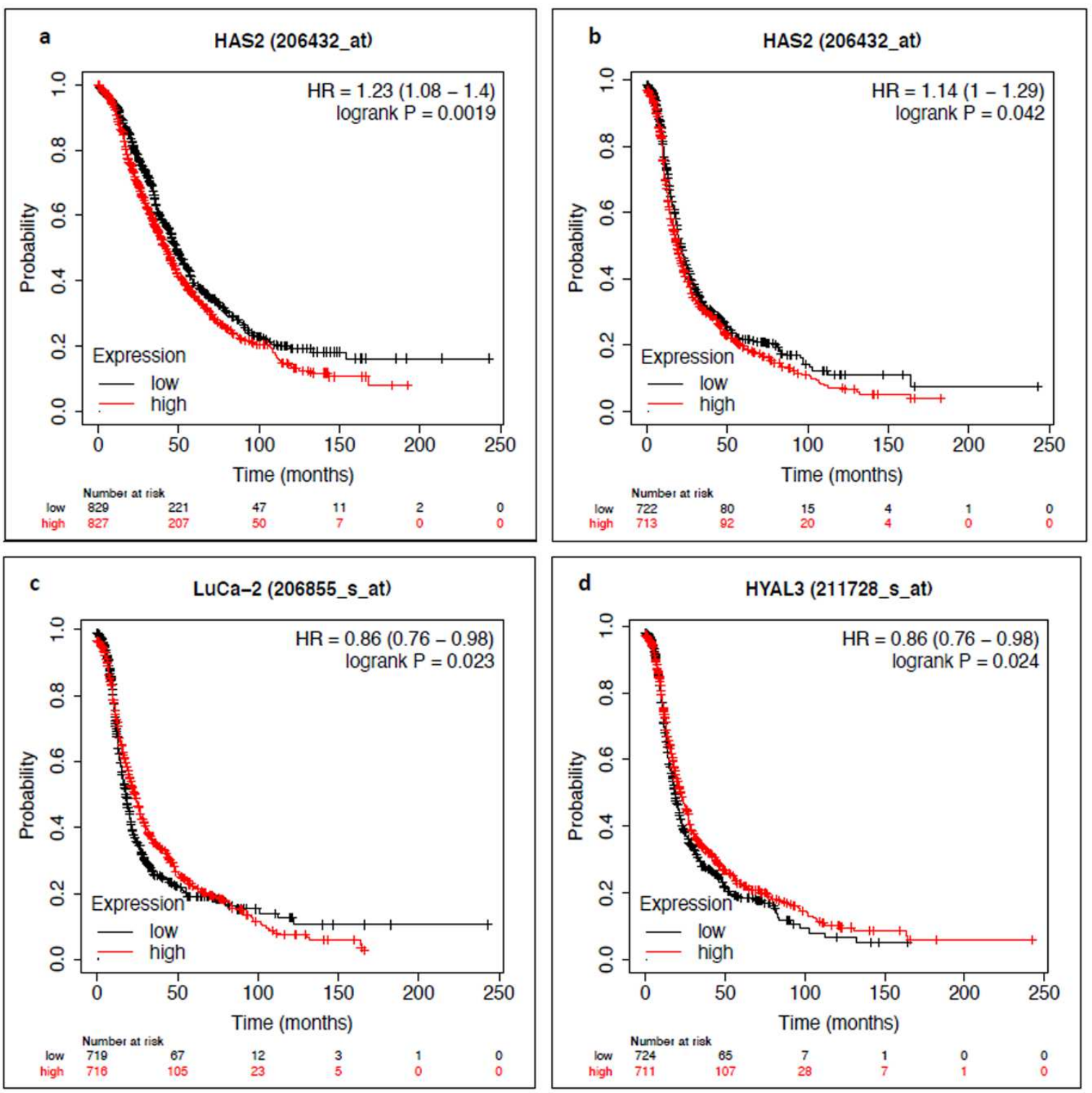

Figure 1 Prognostic value of HAS2, HYAL2 and HYAL3 for the survival of patients with ovarian cancer. The analysis was done by the Kaplan-Meier-Plotter. For each enzyme the Kaplan-Meier-curve, the Hazard Ratio (95\% confidence interval) and the p-value were given. $a$ : Overall survival $(O S)$ in correlation with HAS2 expression ( $n=$ 1656), $b$ : progression free survival (PFS) in correlation with HAS2 expression $(n=1435), c:$ PFS in correlation with HYAL2 (LuCA-2) $(n=1435), d$ : PFS in correlation with HYAL3 $(n=1435)$. 


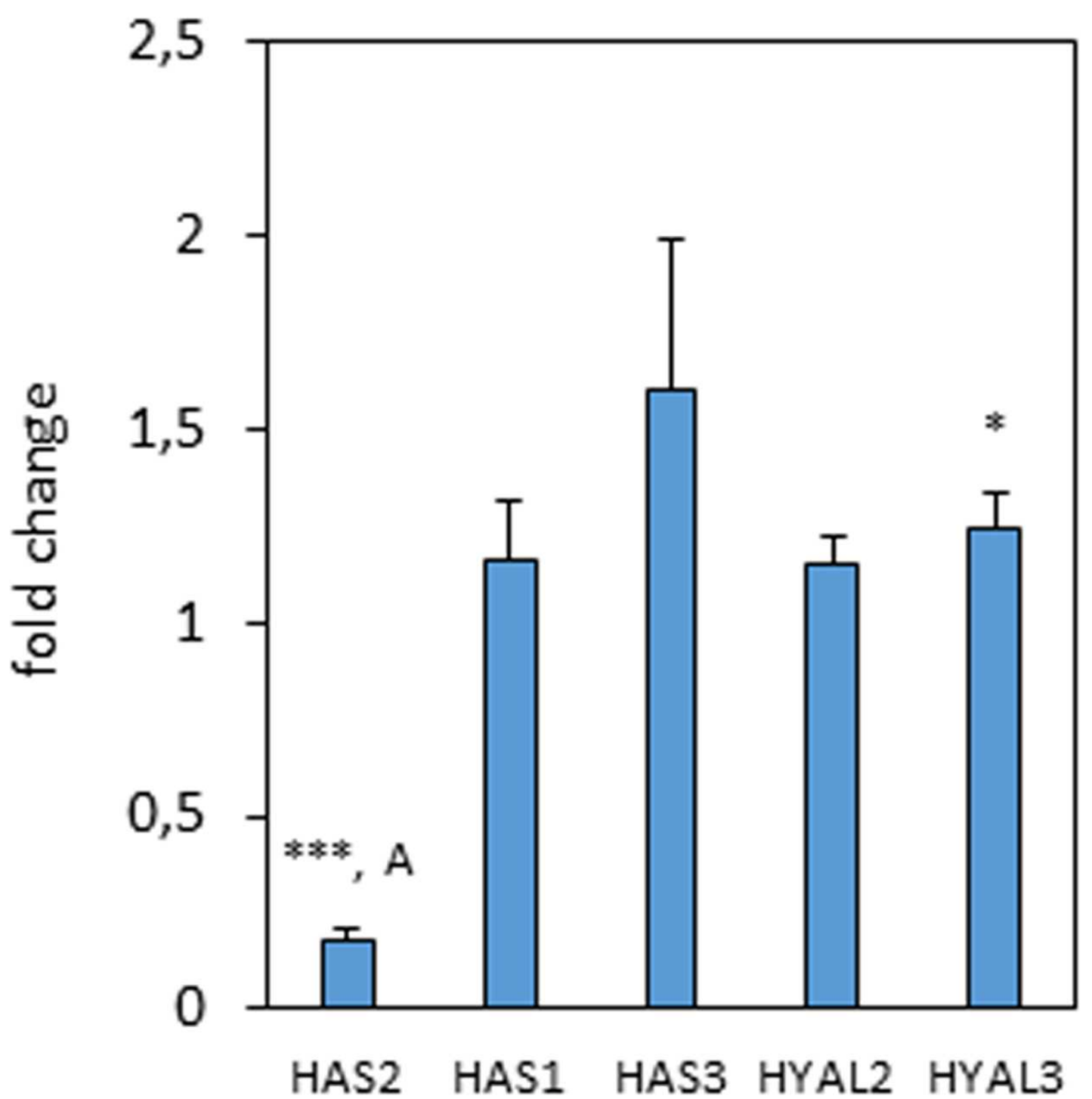

Figure 1 Impact of HAS2 knockdown and its influence on the expression of HAS1, HAS3, HYAL2 and HYAL3 in SKOV3 ovarian cancer cells, as measured by qPCR. The mean value was given with the standard error. Data represent the results of four independent experiments ( $n=2$ or 3 ) under same conditions. * $p \leq 0.05$, ** $\leq 0.001$, $* * * p \leq 0.0001$. A: The mean value was calculated out of 7 values, in 6 samples HAS 2 expression was not detectable after HAS2 siRNA knockdown. 


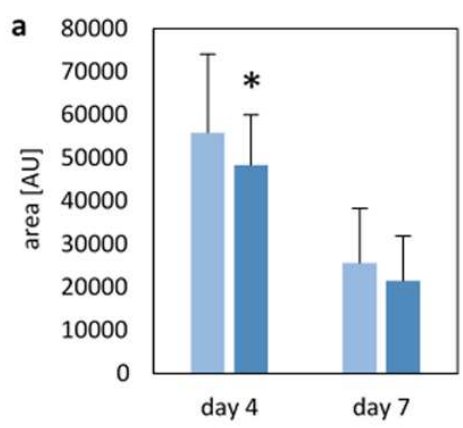

w control $=$ HAS2

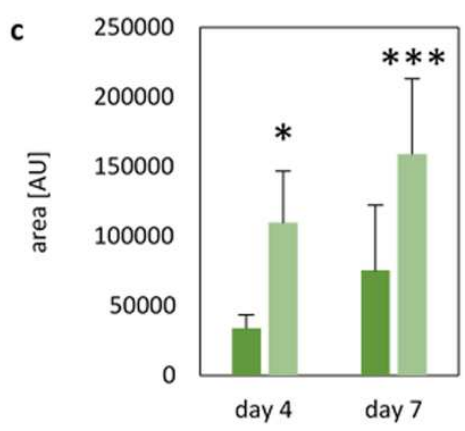

control $=$ HAS2

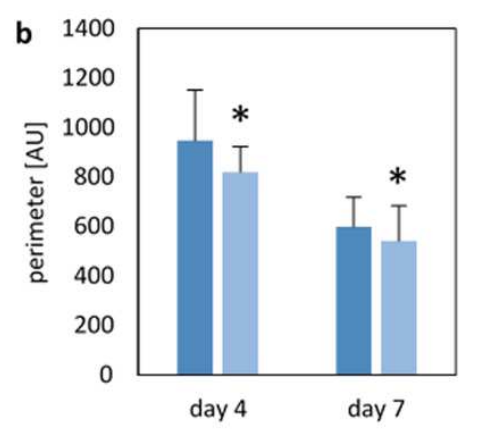

control HAS2

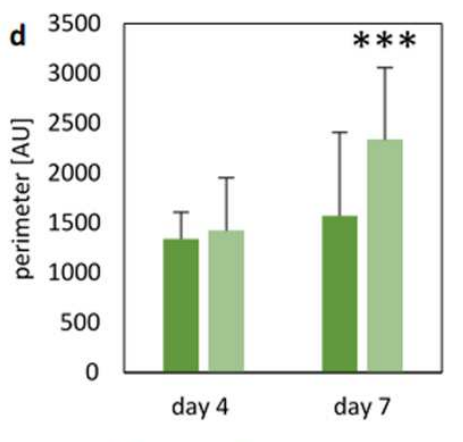

control $=$ HAS2 control

day4

day 7

HAS2

day4

day7

f

\begin{tabular}{l|l|l|}
\hline & $\begin{array}{l}\text { diffuse } \\
\text { edge }\end{array}$ & $\begin{array}{l}\text { no } \\
\text { diffuse } \\
\text { edge }\end{array}$ \\
\hline control day 4 & $25 \%$ & $75 \%$ \\
\hline control day 7 & $54 \%$ & $46 \%$ \\
\hline HAS2 day 4 & $76 \%$ & $24 \%$ \\
\hline HAS2 day 7 & $100 \%$ & $0 \%$
\end{tabular}

Figure 2 Hanging drop method was used to show differences in cell cohesion and sphere formation capability of HAS2 knockdown cells compared to control cells. a-d: The area or perimeter of spheres respectively the diffuse edge of HAS2 knockdown and control cells was measured at day 4 and day 7. a,b) area and perimeter of the spheres excluding the diffuse edge. $\boldsymbol{c}, \boldsymbol{d})$ area and perimeter of the spheres including the diffuse edge. Data represent mean $\pm S D$ from four different experiments which were done under same conditions. $*^{*} \leq 0.05$, ** $\leq \leq$ $0.001,{ }^{* *} p \leq 0.0001 \mathrm{e}:$ Representative pictures of spheres in drops of HAS2 knockdown cells and control cells. Note presence of a solid dark core and a light, diffuse edge. $f$ : The frequency of spheres that built a diffuse edge is shown in \%. The values were built out of data of 4 experiments á 12 drops for HAS 2 knockdown and control cells $(n=48) . A U=$ arbitrary unit. 
a

Taxol

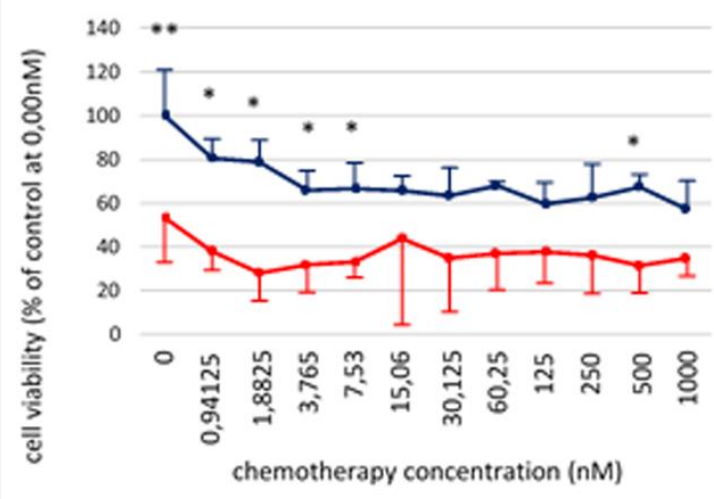

b

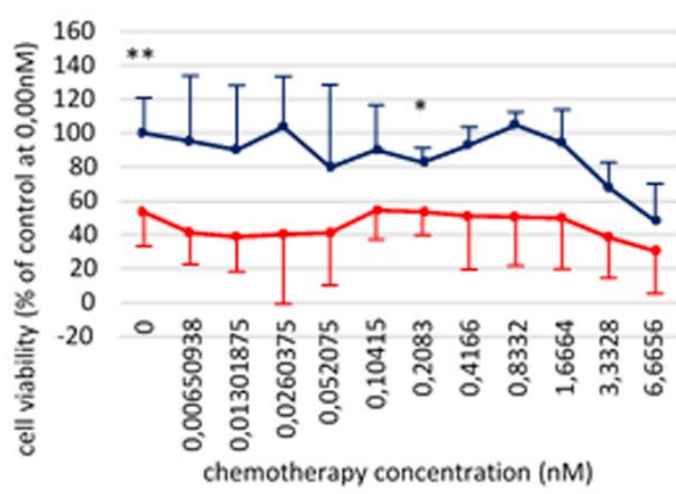

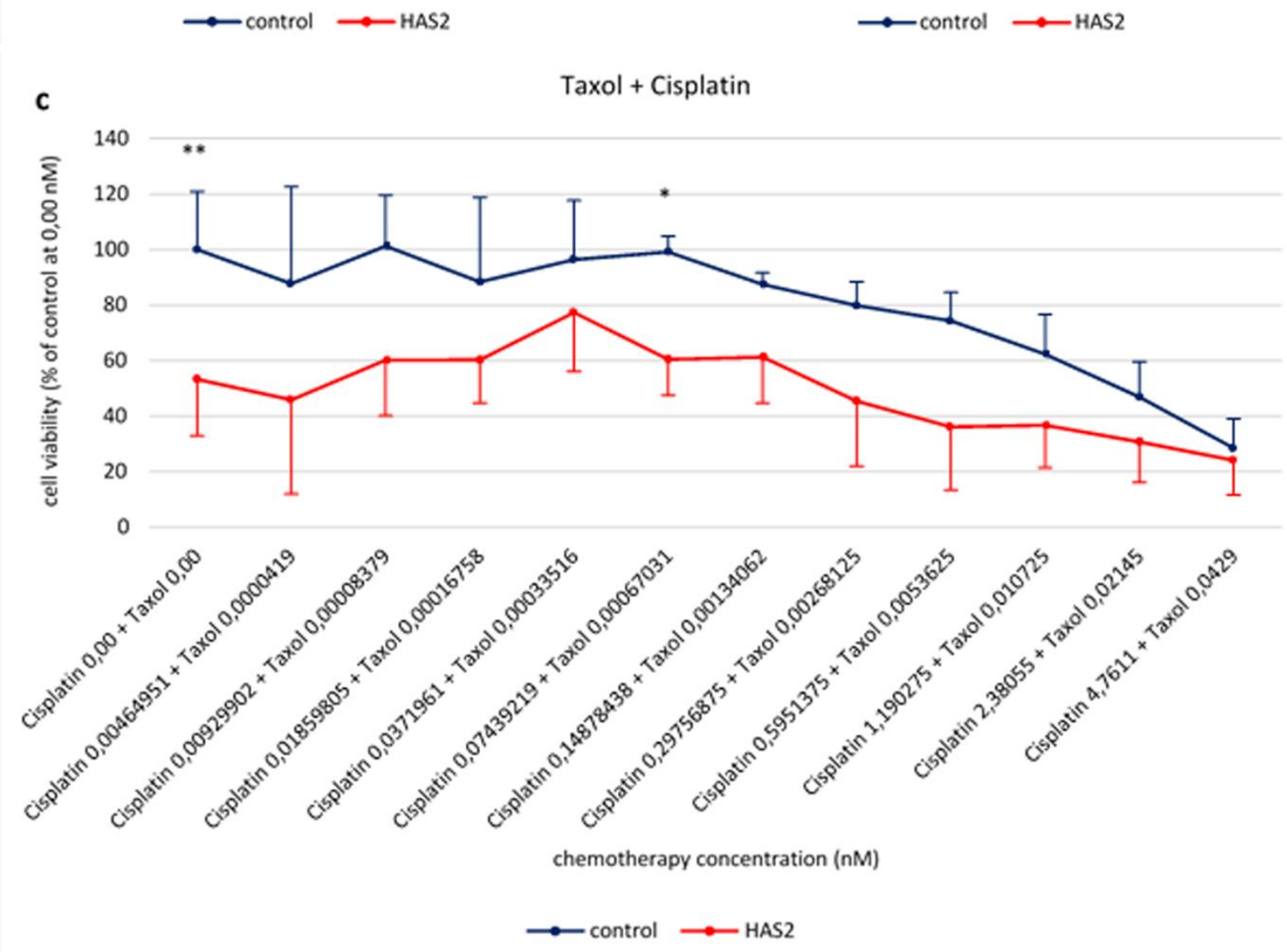

Figure 3 Viability of HAS2 knockdown cells and control cells at different chemotherapy treatments, measured by MTT assay. All values are given in \% based on the concentration of control cells at 0,00 nM chemotherapy treatment. Results represent mean value $\pm S D$ for three experiments under same conditions. ${ }^{*} p \leq 0.05, * * p \leq 0.001$. $\boldsymbol{a}:$ treatment with Taxol, $\boldsymbol{b}:$ treatment with Cisplatin, $\boldsymbol{c}:$ treatment with Taxol + Cisplatin 
a
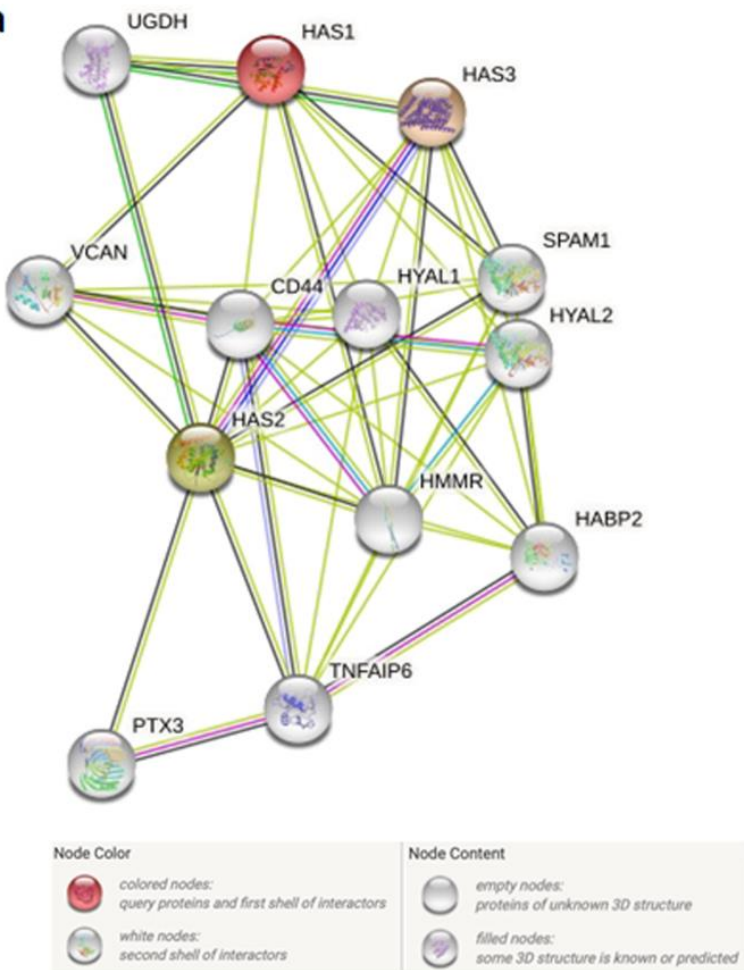

b

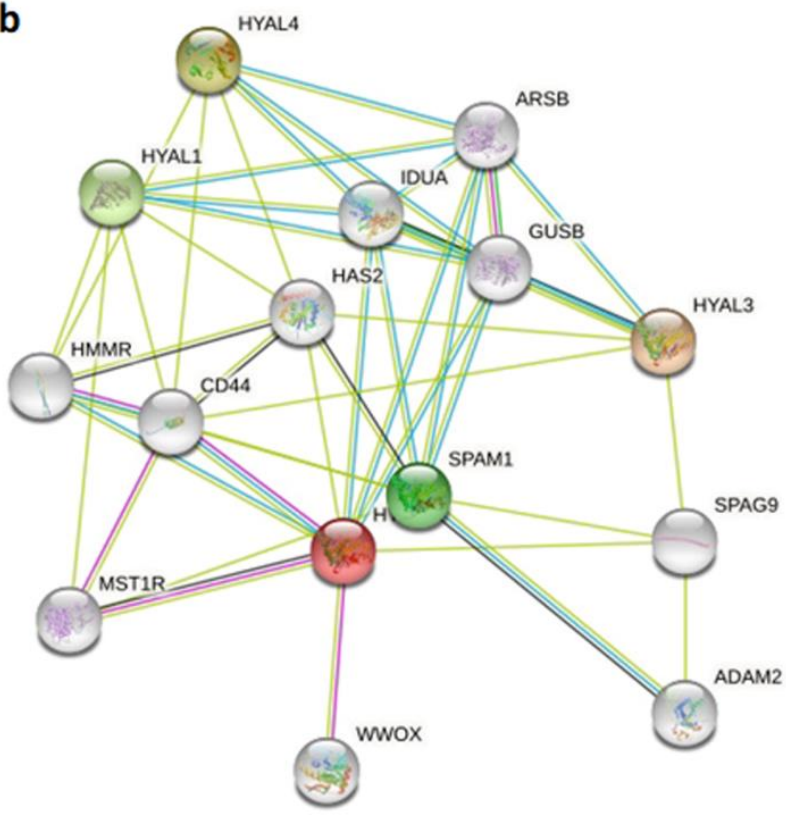

Known Interactions

Predicted interactions Others

e- $\odot$ from curated databases

Q- - experimentally determined

$\ominus-\ominus$ genenelghborhood $\Theta-\ominus$ textmining

-O genefusions $\quad-\ominus$ coexpression

¿-

Figure 5 STRING analysis for protein-protein interactions of hyaluronan pathway contituents. With the use of STRING database (https://string-db.org) the interactions of the proteins, analyzed in this study, are shown. Medium confidence threshold of 0.004. a: HAS1-3, b: HYAL1-5. 
Table 1 Correlation between the expression of HAS1-HAS3, HYAL1-HYAL5 and HYALP1 and the overall survival (OS) or progression free survival (PFS) of ovarian cancer patients. Data were analyzed by the Kaplan-MeierPlotter. Number of cases, HR ad p-value are given. Statistically significant values are marked in bold typing.

\begin{tabular}{|l|l|l|l|l|l|l|}
\hline & OS & & & PFS & & \\
\hline genes & case n & HR & p-value & case n & HR & p-value \\
\hline HAS 1 & 1656 & 1.05 & 0.45 & 1435 & 1.1 & 0.13 \\
\hline HAS 2 & 1656 & 1.23 & $\mathbf{0 . 0 0 1 9}$ & 1435 & 1.14 & $\mathbf{0 . 0 4 2}$ \\
\hline HAS 3 & 655 & 1 & 0.99 & 614 & 0.99 & 0.94 \\
\hline HYAL1 & 1656 & 1.05 & 0.49 & 1435 & 1.01 & 0.84 \\
\hline HYAL2 & 1656 & 0.9 & 0.099 & 1435 & 0.86 & $\mathbf{0 . 0 2 3}$ \\
\hline HYAL3 & 1656 & 0.88 & 0.046 & 1435 & 0.86 & $\mathbf{0 . 0 2 4}$ \\
\hline HYAL4 & 1656 & 0.95 & 0.4 & 1435 & 0.94 & 0.36 \\
\hline HYAL5 & 1656 & 1.02 & 0.79 & 1435 & 0.96 & 0.48 \\
\hline HYALP1 & 655 & 0.88 & 0.22 & 614 & 0.9 & 0.28 \\
\hline
\end{tabular}


Table 2 Correlation between the expression of HAS1-HAS3 and the overall survival (OS) or progression free survival (PFS) of ovarian cancer patients. Distinction was made between the subgroup's histology (serous or endometrioid), staging $(I+I I$ or III $+I V)$, grading (I or II + III) and chemotherapy approaches (Taxol, Platin or Taxol + Platin). Data were analyzed by the Kaplan-Meier-Plotter. Number of cases, HR and p-value are given. Statistically significant values are marked in bold typing.

\begin{tabular}{|c|c|c|c|c|c|c|c|c|}
\hline & & & OS & & & PFS & & \\
\hline genes & & & case $n$ & HR & p-value & case $n$ & HR & p-value \\
\hline \multirow[t]{9}{*}{ HAS 1} & histology & serous & 1207 & 1.02 & 0.79 & 1104 & 1.3 & $\mathbf{0 . 0 0 0 3 3}$ \\
\hline & & endometrioid & 37 & 0.61 & 0.58 & 51 & 0.97 & 0.96 \\
\hline & staging & $\mathrm{I}+\mathrm{II}$ & 135 & 0.71 & 0.38 & 163 & 1 & 0.99 \\
\hline & & III + IV & 1220 & 1 & 0.96 & 1081 & 1.24 & 0.0033 \\
\hline & grading & I & 56 & 1.5 & 0.43 & 37 & 1.65 & 0.38 \\
\hline & & II + III & 1339 & 1.04 & 0.58 & 1093 & 1.3 & 0.0003 \\
\hline & chemotherapy & Platin & 1409 & 1.06 & 0.41 & 1259 & 1 & 0.96 \\
\hline & & Taxol & 793 & 1.12 & 0.25 & 715 & 1.26 & 0.007 \\
\hline & & $\begin{array}{|ll|}\text { Taxol } & + \\
\text { Platin } & \\
\end{array}$ & 776 & 1.07 & 0.49 & 698 & 1.25 & 0.011 \\
\hline \multirow[t]{9}{*}{ HAS 2} & histology & serous & 1207 & 1.26 & 0.0027 & 1104 & 1.31 & 0.00021 \\
\hline & & endometrioid & 37 & 0.1 & 0.013 & 51 & 0.54 & 0.21 \\
\hline & staging & $\mathrm{I}+\mathrm{II}$ & 135 & 0.96 & 0.91 & 163 & 1.47 & 0.19 \\
\hline & & III + IV & 1220 & 1.18 & 0.03 & 1081 & 1.2 & 0.012 \\
\hline & grading & I & 56 & 1.12 & 0.82 & 37 & 1.35 & 0.59 \\
\hline & & II + III & 1339 & 1.21 & 0.01 & 1093 & 1.26 & 0.0016 \\
\hline & \begin{tabular}{|l|} 
chemotherapy \\
\end{tabular} & Platin & 1409 & 1.27 & 0.0007 & 1259 & 1.05 & 0.46 \\
\hline & & Taxol & 793 & 1.22 & 0.041 & 715 & 1.23 & 0.016 \\
\hline & & $\begin{array}{|ll|}\text { Taxol } \quad+ \\
\text { Platin }\end{array}$ & 776 & 1.21 & 0.045 & 698 & 1.23 & 0.019 \\
\hline \multirow[t]{9}{*}{ HAS 3} & histology & serous & 523 & 0.95 & 0.66 & 483 & 1 & 0.96 \\
\hline & & endometrioid & 30 & 0.19 & 0.11 & 44 & 0.41 & 0.099 \\
\hline & staging & $\mathrm{I}+\mathrm{II}$ & 83 & 1.36 & 0.56 & 115 & 0.99 & 0.97 \\
\hline & & III + IV & 487 & 0.92 & 0.45 & 494 & 1.06 & 0.58 \\
\hline & grading & $\mathrm{I}$ & 41 & 1.94 & 0.23 & 28 & 0.78 & 0.72 \\
\hline & & II + III & 554 & 1.04 & 0.7 & 476 & 1.07 & 0.51 \\
\hline & chemotherapy & Platin & 478 & 0.96 & 0.76 & 502 & 1.11 & 0.29 \\
\hline & & Taxol & 357 & 0.88 & 0.38 & 381 & 0.99 & 0.94 \\
\hline & & \begin{tabular}{|l|} 
Taxol \\
Platin \\
\end{tabular} & 356 & 0.88 & 0.4 & 380 & 0.99 & 0.9 \\
\hline
\end{tabular}


Table 3 Correlation between the expression of HYAL1-HYAL3 and the overall survival (OS) or progression free survival (PFS) of ovarian cancer patients. Distinction was made between the subgroup's histology (serous or endometrioid), staging $(I+I I$ or III $+I V)$, grading (I or II + III) and chemotherapy approaches (Taxol, Platin or Taxol + Platin). Data were analyzed by the Kaplan-Meier-Plotter. Number of cases, HR and p-value are given. Statistically significant values are marked in bold typing.

\begin{tabular}{|c|c|c|c|c|c|c|c|c|}
\hline & & & OS & & & PFS & & \\
\hline genes & & & case $n$ & HR & p-value & case $n$ & HR & p-value \\
\hline \multirow[t]{9}{*}{ HYAL1 } & histology & serous & 1207 & 0.99 & 0.85 & 1104 & 1.02 & 0.75 \\
\hline & & endometrioid & 37 & 0.73 & 0.73 & 51 & 0.81 & 0.65 \\
\hline & staging & $\mathrm{I}+\mathrm{II}$ & 135 & 0.8 & 0.56 & 163 & 0.81 & 0.45 \\
\hline & & III + IV & 1220 & 1.01 & 0.92 & 1081 & 0.99 & 0.91 \\
\hline & grading & $\mathrm{I}$ & 56 & 0.75 & 0.54 & 37 & 1.49 & 0.48 \\
\hline & & $\mathrm{II}+\mathrm{III}$ & 1339 & 1.04 & 0.6 & 1093 & 0.96 & 0.61 \\
\hline & chemotherapy & Platin & 1409 & 1.08 & 0.31 & 1259 & 0.95 & 0.44 \\
\hline & & Taxol & 793 & 1.16 & 0.12 & 715 & 1 & 0.97 \\
\hline & & $\begin{array}{|ll|}\text { Taxol } & + \\
\text { Platin } & \\
\end{array}$ & 776 & 1.14 & 0.18 & 698 & 0.97 & 0.76 \\
\hline \multirow[t]{9}{*}{ HYAL2 } & histology & serous & 1207 & 0.91 & 0.24 & 1104 & 1.04 & 0.58 \\
\hline & & endometrioid & 37 & $<0.1$ & 0.0038 & 51 & 0.17 & \begin{tabular}{|l|}
$5.00 E-$ \\
04 \\
\end{tabular} \\
\hline & staging & $\mathrm{I}+\mathrm{II}$ & 135 & 0.98 & 0.97 & 163 & 0.71 & 0.24 \\
\hline & & III + IV & 1220 & 0.89 & 0.12 & 1081 & 1.07 & 0.36 \\
\hline & grading & $\mathrm{I}$ & 56 & 0.18 & 0.003 & 37 & 0.53 & 0.25 \\
\hline & & $\mathrm{II}+\mathrm{III}$ & 1339 & 0.93 & 0.33 & 1039 & 1.02 & 0.77 \\
\hline & chemotherapy & Platin & 1409 & 0.98 & 0.79 & 1259 & 0.88 & 0.063 \\
\hline & & Taxol & 793 & 0.92 & 0.39 & 715 & 0.93 & 0.41 \\
\hline & & $\begin{array}{|ll|}\text { Taxol } & + \\
\text { Platin } & \\
\end{array}$ & 776 & 0.93 & 0.42 & 698 & 0.93 & 0.4 \\
\hline \multirow[t]{9}{*}{ HYAL3 } & histology & serous & 1207 & 0.83 & 0.016 & 1104 & 0.94 & 0.41 \\
\hline & & endometrioid & 37 & 0.44 & 0.35 & 51 & 0.67 & 0.4 \\
\hline & staging & $\mathrm{I}+\mathrm{II}$ & 135 & 0.55 & 0.14 & 163 & 1.21 & 0.5 \\
\hline & & III + IV & 1220 & 0.83 & 0.016 & 1081 & 0.92 & 0.27 \\
\hline & grading & $\mathrm{I}$ & 56 & 0.9 & 0.84 & 37 & 2.41 & 0.13 \\
\hline & & II + III & 1339 & 0.83 & 0.012 & 1039 & 0.92 & 0.27 \\
\hline & chemotherapy & Platin & 1409 & 0.85 & 0.02 & 1259 & 0.8 & 0.0006 \\
\hline & & Taxol & 793 & 0.84 & 0.064 & 715 & 0.9 & 0.23 \\
\hline & & \begin{tabular}{ll|} 
Taxol & + \\
Platin &
\end{tabular} & 776 & 0.84 & 0.065 & 698 & 0.9 & 0.21 \\
\hline
\end{tabular}


Table 4 Correlation between the expression of HYAL4, HYAL5 and HYALP1 and the overall survival (OS) or progression free survival (PFS) of ovarian cancer patients. Distinction was made between the subgroup's histology (serous or endometrioid), staging $(I+I I$ or III $+I V)$, grading $(I$ or II + III) and chemotherapy approaches (Taxol, Platin or Taxol + Platin). Data were analyzed by the Kaplan-Meier-Plotter. Number of cases, $H R$ and p-value are given. Statistically significant values are marked in bold typing.

\begin{tabular}{|c|c|c|c|c|c|c|c|c|}
\hline & & & OS & & & PFS & & \\
\hline genes & & & case $n$ & HR & p-value & case $n$ & HR & p-value \\
\hline \multirow[t]{9}{*}{ HYAL4 } & histology & serous & 1207 & 0.88 & 0.097 & 1104 & 0.98 & 0.81 \\
\hline & & endometrioid & 37 & 0.64 & 0.62 & 51 & 0.81 & 0.67 \\
\hline & \begin{tabular}{|l} 
staging \\
\end{tabular} & $\mathrm{I}+\mathrm{II}$ & 135 & 0.68 & 0.33 & 163 & 0.79 & 0.41 \\
\hline & & III + IV & 1220 & 0.85 & 0.035 & 1081 & 0.98 & 0.77 \\
\hline & grading & $\mathrm{I}$ & 56 & 0.98 & 0.97 & 37 & 0.43 & 0.15 \\
\hline & & II + III & 1339 & 0.87 & 0.058 & 1093 & 0.97 & 0.65 \\
\hline & chemotherapy & Platin & 1409 & 0.94 & 0.42 & 1259 & 0.9 & 0.12 \\
\hline & & Taxol & 793 & 0.88 & 0.19 & 715 & 0.96 & 0.66 \\
\hline & & $\begin{array}{|ll|}\text { Taxol } & + \\
\text { Platin } & \\
\end{array}$ & 776 & 0.88 & 0.19 & 698 & 0.97 & 0.71 \\
\hline \multirow[t]{9}{*}{ HYAL5 } & histology & serous & 1207 & 1.04 & 0.57 & 1104 & 1.08 & 0.27 \\
\hline & & endometrioid & 37 & 0.62 & 0.6 & 51 & 0.3 & 0.015 \\
\hline & staging & $\mathrm{I}+\mathrm{II}$ & 135 & 0.48 & 0.071 & 163 & 0.58 & 0.062 \\
\hline & & III + IV & 1220 & 0.99 & 0.91 & 1081 & 1.01 & 0.84 \\
\hline & grading & $\mathrm{I}$ & 56 & 1.48 & 0.42 & 37 & 1.18 & 0.77 \\
\hline & & $\mathrm{II}+\mathrm{III}$ & 1339 & 1.03 & 0.66 & 1093 & 1.03 & 0.71 \\
\hline & chemotherapy & Platin & 1409 & 1.02 & 0.8 & 1259 & 0.94 & 0.31 \\
\hline & & Taxol & 793 & 1.15 & 0.14 & 715 & 1.08 & 0.4 \\
\hline & & $\begin{array}{|ll|}\text { Taxol } & + \\
\text { Platin } & \\
\end{array}$ & 776 & 1.19 & 0.07 & 698 & 1.1 & 0.26 \\
\hline \multirow[t]{9}{*}{ HYALP1 } & histology & serous & 523 & 0.94 & 0.56 & 483 & 0.94 & 0.55 \\
\hline & & endometrioid & 30 & 1.4 & 0.74 & 44 & 0.73 & 0.55 \\
\hline & staging & $\mathrm{I}+\mathrm{II}$ & 83 & 1.07 & 0.9 & 115 & 1.26 & 0.53 \\
\hline & & III + IV & 487 & 0.89 & 0.3 & 494 & 0.9 & 0.31 \\
\hline & grading & $\mathrm{I}$ & 41 & 0.41 & 0.14 & 28 & 0.35 & 0.17 \\
\hline & & $\mathrm{II}+\mathrm{III}$ & 554 & 0.94 & 0.55 & 476 & 0.94 & 0.54 \\
\hline & chemotherapy & Platin & 478 & 0.89 & 0.34 & 502 & 0.89 & 0.24 \\
\hline & & Taxol & 357 & 1 & 0.98 & 381 & 0.92 & 0.48 \\
\hline & & $\begin{array}{ll}\text { Taxol } & + \\
\text { Platin } & \\
\end{array}$ & 356 & 1 & 1 & 380 & 0.92 & 0.45 \\
\hline
\end{tabular}




\section{Supplementary information}

The hyaluronan-related genes HAS2, HYAL1-5, HYALP1 are associated with prognosis, cell viability and spheroid formation capacity in ovarian cancer

Jette Riecks, Balázs Győrffy, Ludwig Kiesel, Alberto Passi, Davide Vigetti, Martin Götte

a HAS2 knockdown cells with prior Taxol treatment

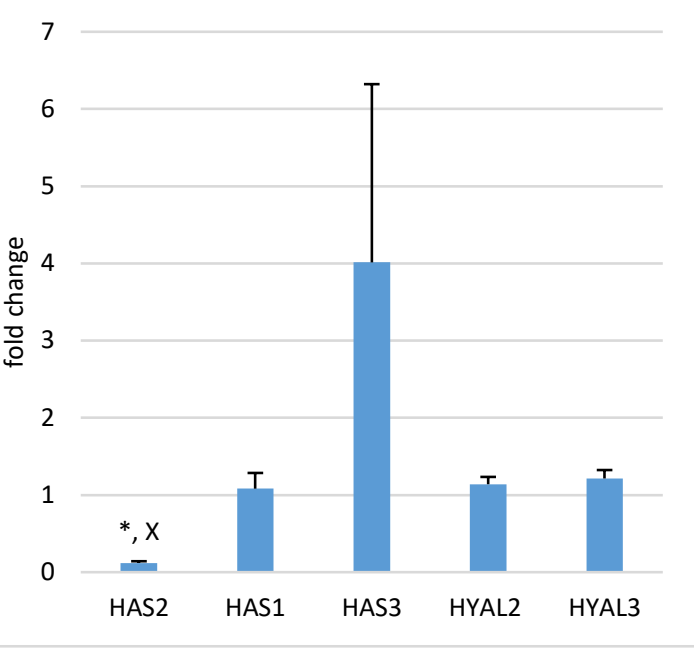

C

HAS2 knockdown cells with prior Taxol and Cisplatin treatment

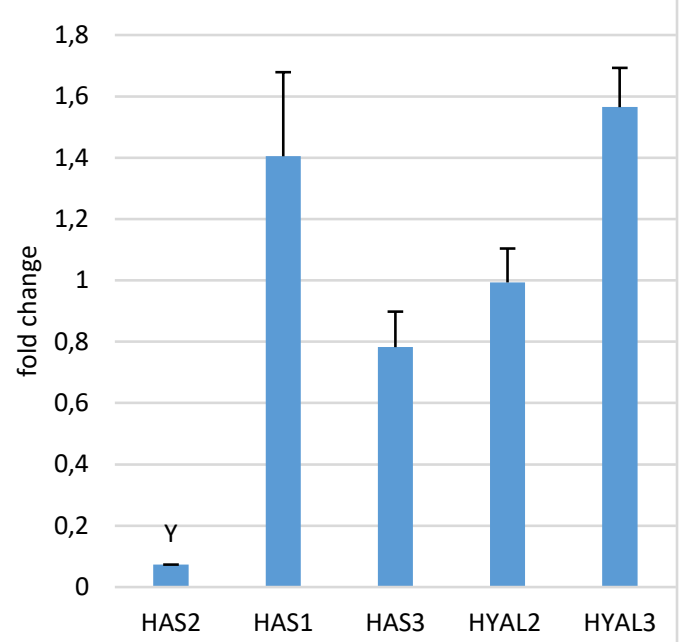

b HAS2 knockdown cells with prior Cisplatin treatment

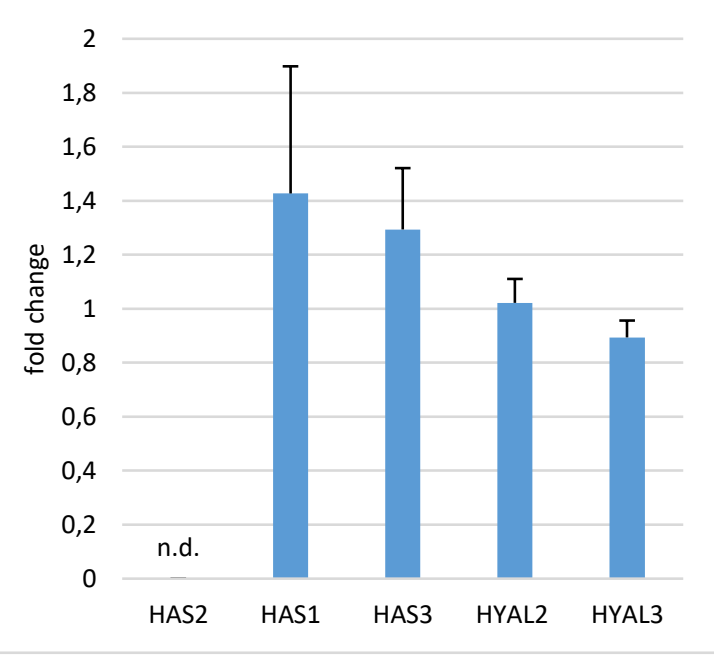

Supplementary Figure S1 HAS2 knockdown and the influence on the expression of HAS1, HAS3, HYAL2 and HYAL3 measured by qPCR. Cells got treated with different chemotherapy approaches 24 hours after transfection. The mean value was given with the standard error. Data represent the results of three independent experiments $(n=3)$ under same conditions. ${ }^{*} p \leq 0.05$ a: treatment with $8000 \mathrm{nM}$ Taxol, $X=$ in 4 of 6 samples HAS2 expression was not detectable, mean value was built out of the other 2 values, $\boldsymbol{b}$ : treatment with 53.3244 $n M$ Cisplatin, n.d. = in 5 of 6 samples expression of HAS2 was not detectable, one value was measured with a fold of 0.72, this value was excluded. $\mathrm{c}$ : treatment with the combination of $0.343 \mathrm{nM}$ Taxol and $38.08 \mathrm{nM}$ Cisplatin, $Y=$ in 5 of 6 samples expression of HAS2 was not detectable 
Table S1: Sequences of primer pairs

\section{SYBR-Green}

\begin{tabular}{|l|l|}
\hline Actin & $\begin{array}{l}\text { Forward: TCA AGA TCA TTG CTC CTC CTG AG } \\
\text { Reverse: ACA TCT GCT GGA AGG TGG ACA }\end{array}$ \\
\hline HAS1 & $\begin{array}{l}\text { Forward: CTG CGA TAC TGG GTA GCC TTC A } \\
\text { Reverse: CCA GGA ACT TCT GGT TGT ACC AG }\end{array}$ \\
\hline HAS3 & $\begin{array}{l}\text { Forward: ACT CTG CAT CGC TGC CTA CC } \\
\text { Reverse: TAC ATG ACC TCA CGC TTG CC }\end{array}$ \\
\hline HYAL2 & $\begin{array}{l}\text { Forward: GGA CCT CAT CTC TAC CAT TGG C } \\
\text { Reverse: CTT TGA GGT ACT GGC AGG TCT C }\end{array}$ \\
\hline HYAL3 & $\begin{array}{l}\text { Forward: GCA GTC CAT TGG TGT GAG TGC A } \\
\text { Reverse: CCA AGG TGT CCA CCA GGT AGT C }\end{array}$ \\
\hline
\end{tabular}

Taq-man assay code numbers (Thermo Fisher)

\begin{tabular}{|l|l|}
\hline Actin & hs $99999903 \mathrm{ml}$ \\
\hline HAS2 & hs $00193435 \mathrm{ml}$ \\
\hline
\end{tabular}

